
3

\title{
Measurements and modelling of particulate matter building ingress during a severe dust storm event
}

Christos D. Argyropoulos ${ }^{1,2}$ Hala Hassan ${ }^{1,3}$, Prashant Kumar ${ }^{3,4}$ and Konstantinos E. Kakosimos ${ }^{1, *}$

${ }^{1}$ Department of Chemical Engineering and Mary Kay O’Connor Process Safety Center, Texas (1) A\&M University at Qatar, Education City, Doha PO Box 23874, Qatar.

${ }^{2}$ System Reliability \& Industrial Safety Lab, Institute of Nuclear \& Radiological Sciences \& Technology, Energy \& Safety, National Centre for Scientific Research “Demokritos”, Patriarchou Grigoriou \& Neapoleos Str., 15310 Ag. Paraskevi, Athens, Greece.

${ }^{3}$ Global Centre for Clean Air Research (GCARE), Department of Civil \& Environmental Engineering, Faculty of Engineering and Physical Sciences, University of Surrey, Guildford GU2 7XH, Surrey, United Kingdom.

${ }^{4}$ Department of Civil, Structural \& Environmental Engineering, School of Engineering, Trinity College Dublin, Dublin, Ireland

Abstract: Dust storms are a common phenomenon that occurs in many dry and arid areas, demonstrates very high levels of particulate matter (PM), can spread significantly further than its origin, affects both outdoor and indoor air quality, and can cause serious health problems although it is a low frequency event. Focus of this study is the prediction of PM $\left(\mathrm{PM}_{2.5}\right.$ and $\left.\mathrm{PM}_{10}\right)$ infiltration at typical commercial and office building environments during severe dust storms. Therefore, a two-month field campaign was conducted to capture such an event in Doha, Qatar,

\footnotetext{
* Corresponding author: phone: +974 44230678; e-mail: kkakosimos@qatar.tamu.edu (K.E. Kakosimos)
} 


\section{$31 \quad$ Highlights}

\section{CONTAM}

and a modelling methodology is proposed based on the one-way coupling of a multi-zone and a computational fluid dynamics software. The predicted levels are in fair agreement with the measurements for both the dust storm and typical days, attributed to the accurate estimation of the external wind pressure and representation of the building envelope. The agreement further improves when ventilation filters' efficiency is estimated rather than extracted from specification sheets. Finally, predictions are found to conform with physical reality and to offer useful insights into PM building infiltration during dust storm events when cross examined with measurements.

- High temporal resolution of outdoor/indoor PM measurements during a severe dust storm

- Dust storm $\mathrm{PM}_{2.5 /} \mathrm{PM}_{10}$ ratios are typical to literature but not constant indoors

- Coupling of indoor air quality modelling with accurate building pressure estimations

- Predictions with standard input parameters show fair agreement with measurements

- Employment of corrected HVAC filter performance improved predictions

Keywords: dust storm; indoor air quality; building ingress; field measurement; QUIC;

\section{INTRODUCTION}

Dust storm events are characterised by enormous amounts of airborne dust and reduce of visibility, in several cases from a distance less to $1 \mathrm{~km}$ [1]. The most common causes for dust storm events are the lift of sand and dust from the land surface to atmosphere through turbulent strong winds and deflation process [2, 3], as well as convective "Haboobs"[4-6]. These events are responsible for large scale transport of particulate matter, pathogens and other pollutants, 
affecting the downwind ecosystem, population [7], and human health [8]. Effects that are probably beyond to what is already known for the association of $\mathrm{PM}_{10}$ and $\mathrm{PM}_{2.5}$ levels with respiratory problems $[9,10]$ cardiovascular diseases $[11,12]$ and dermatological disorders $[13$, 14].

The occurrence of dust storm events and their magnitude vary during the year and differ for each region $[15,16]$. According to Song, et al. [17] the storm events for the northeast Asia are classified as floating dust, blowing dust, dust storm and severe dust storm, based on the values of total suspended particles (TSP), particulate matter (PM) and wind velocity. For example, during a severe dust storm, the observed values of TSP are equal or larger than $6000 \mu \mathrm{g} \mathrm{m}^{-3}$ and the $\mathrm{PM}_{10}$ (PM with aerodynamic diameter less than $10 \mu \mathrm{m}$ ) concentrations can reach a value of $5000 \mu \mathrm{g} \mathrm{m}^{-}$ ${ }^{3}$ or higher, while the wind velocity exceeds values of $10 \mathrm{~m} \mathrm{~s}^{-1}$. In another occasion, Chen, et al. [18] reported $\mathrm{PM}_{10}$ concentrations to be approximately twice the levels of normal days during an Asian Dust Storm. Krasnov, et al. [19] also observed very high levels of PM on dust days in Northern Africa, up to $2643 \mu \mathrm{g} \mathrm{m}^{-3}$, while significantly less, around $42 \mu \mathrm{g} \mathrm{m}^{-3}$, on normal days. The above values of $\mathrm{PM}_{10}$ levels imply several days per year of exceedance for any known air quality standard (e.g. European Directive 2008/50/EC at $50 \mu \mathrm{g} \mathrm{m}^{-3}$, no more than 35 days/year) $[1,19,20]$. Note that most countries in MEA follow the U.S. National Air Quality Standards, which for $\mathrm{PM}_{10}$ are $150 \mu \mathrm{g} \mathrm{m}^{-3}$ (annual average) and $50 \mu \mathrm{g} \mathrm{m}^{-3}$ (24hr average) [21]. Undoubtedly, dust storms not only affect the health of those outdoors but also the people living in nearby buildings and indoor environments. Outdoor particulate matter can penetrate indoor through the ventilation system, window gaps and cracks. This process of air infiltration between the building and outdoor environment is defined as ingress [22]. Kuo and Shen [23] investigated the insights into outdoor/indoor $\mathrm{PM}_{2.5}$ and $\mathrm{PM}_{10}$ levels in relation to dust storm events. They found a three-fold increase in $\mathrm{PM}_{2.5}$ and $\mathrm{PM}_{10}$ levels of pollutants for both indoor 
and outdoor environment during the dust storm. They also highlighted the influence of the ventilation system on the indoor air quality during dust events. Kanatani, et al. [24] reported a 20-fold and 50-fold increase in indoor and outdoor PM values during an Asian dust storm event in Kyoto, Japan. According to this study, the indoor PM levels of an apartment room reached $70 \%$ of the outdoor air PM levels when a window remained open for just 10 minutes. In another study of Krasnov, et al. [25], on the impact of atmospheric dust events, an infiltration factor of 0.82 for fine particles was reported despite houses being protected by closed windows with indoor $\mathrm{PM}_{10}$ concentrations reaching $1000 \mu \mathrm{g} \mathrm{m}^{-3}$, while the infiltration factor for normal days was found to be 0.26 . Wong and Huang [26] stressed on the infiltration differences between naturally ventilated rooms and to those with air-conditioners, with the former showing higher values.

From the above it is obvious that the quantification of the PM infiltration plays a significant role in investigating the risk assessment of population exposure [27, 28], especially in areas where PM concentrations can frequently reach very high levels due to dust storm events. In one of the few related studies Longueville, et al. [14] exhibited strong correlations between dust events and human health for West Africa. Nevertheless, building ingress is highly complex and depends on multiple factors, in addition to the PM atmospheric dispersion, such as building wind pressures, the ventilation systems, and the leakage characteristics of the building envelope [29]. Other driving factors which affect the infiltration rates are the building architecture and the effect of the surrounding buildings [30]. Both Kuo and Shen [23] and Chen and Zhao [31] reviewed the correlations between the outdoor and indoor PM concentrations and discussed the available modelling techniques, however, with emphasis on simple infiltration ratios for buildings and advanced modelling techniques for single openings. Apparently, there is a lack of validated and 
comprehensive simulation methodologies for PM building infiltration; an issue also supported by the recent review of Amoatey, et al. [32].

Therefore, aim of this work is to propose and validate a computational methodology for the simulation of indoor and outdoor (I/O) PM building infiltration under normal day conditions and during severe dust storm events. To achieve this, a widely used multi-zone model, CONTAM by NIST [33], was coupled with a CFD model, Quick Urban Dispersion Model (QUIC) by Los Alamos National Laboratory [34], to compute the indoor PM levels in a complex building while considering the external wind pressures and velocities. In the past, the combination of such models has been proposed to study building ingress of gaseous pollutants [35], air flow between isothermal rooms [36], and air quality in full buildings Wang and Chen [37], among others. The literature on the building ingress of gaseous components is richer and with validated simulation tools that can address the complex phenomena for the whole building at once e.g. $[38,39]$. However, to the best knowledge of authors, this is one of the very few studies to investigate the PM infiltration during a dust storm event by collecting high temporal resolution measurements of the I/O levels and by coupling multi-zone and CFD models with validation of the obtained results.

\section{MATERIALS AND METHODS}

This chapter provides details on the two main approaches employed in this work. At first, section 2.1 describes the field campaign with the objective to collect high temporal resolution of indoor and outdoor PM measurements capturing both normal and dust storm conditions. This data will be used to evaluate the performance of the proposed integrated modelling approach on three different scenarios. Therefore, the details of the modelling tools and scenarios are provided in sections 2.2 and 2.3 respectively. Specifically on the modelling approach, building infiltration 
118 is mainly affected by two factors the wind pressure exerted on the building envelope, driven by

119 the meteorological conditions, and the building design itself i.e. the ventilation systems (HVAC)

120 and openings. Thus, herein an advanced numerical tool is employed for estimation of the wind

121 pressure and detailed technical data are extracted for the building design. Past studies ([22, 40])

122 showed that HVAC and the filtration systems in place are critical, especially in extreme events,

123 and thus the three selected scenarios (section 2.3) address them.

\subsection{Field campaign and measurements}

A monitoring campaign of PM measurements was performed at an office building, Al

127 Rumaila West, Doha City, Qatar. Simultaneous indoor and outdoor $\mathrm{PM}_{2.5}$ and $\mathrm{PM}_{10}$

128 measurements took place from 1 March to 30 June 2015. Details of this campaign can be found

129 in a PM characterization study [41]. At the same period, Qatar Meteorological Department issued

130 eleven warnings for strong winds accompanied with major, medium, or slight dust events $(2,13$,

131 24-April; 2, 5, 23-May; 2, 4, 8, 13 and 21 June). Since focus of this study is the PM infiltration

132 during severe dust events the period between 31-Mar to 16-April has been selected as study

133 period which includes both a major dust event and normal dust levels. The city of Doha is the

134 capital of Qatar situated on the Doha bay with a population of more than 1.7 million people (2010

135 census; estimated to 2.5 million today). The building is located next to a very busy road, $500 \mathrm{~m}$

136 from the beachfront at $18 \mathrm{~m}$ above the mean sea level. It has a rectangular shape (130 m length

137 and $30 \mathrm{~m}$ width) and seven floors, all used as office space; it is aligned along the NNW to SSE

138 axis. The nearby area is characterised by intense construction activities and low-rise buildings,

139 which is representative of the whole metropolitan area. The building is mechanically ventilated

140 (8-10 air changes per hour-ACH; provided by the building's HVAC study) using 75-90\% fresh

141 air, and with minimum diurnal/weekly variations. Indoor conditions were very well regulated at 
142 temperature $22.5 \pm 1{ }^{\circ} \mathrm{C}$ and relative humidity $51 \pm 9 \%$. It is also quite busy over the weekdays

143 (Sunday to Thursday) and 07:00 to 14:00h (local time), while it is closed to the public and

144 employees during the weekend (Friday to Saturday). For the campaign, we established one

145 outdoor and one indoor sampling site. The outdoor site is located on the NNW fence line, ten

146 meters from the narrow building facade. The indoor site is on the $3^{\text {rd }}$ floor reception area, in the

147 middle of the building length. The whole floor is carpeted and it includes two rows of office and

148 meeting rooms, along the length of the building and one at each side, while in the middle there

149 are open areas with office cubicles (Figure 1). The selected floor was considered representative of

150 the building's indoor conditions. The reception area is also quite busy over the day; it connects

151 the office areas with the utility rooms (restroom, prayer room, elevators, and stairs), but it is not

152 directly exposed to either of these areas and thus was selected as the indoor sampling location.

153

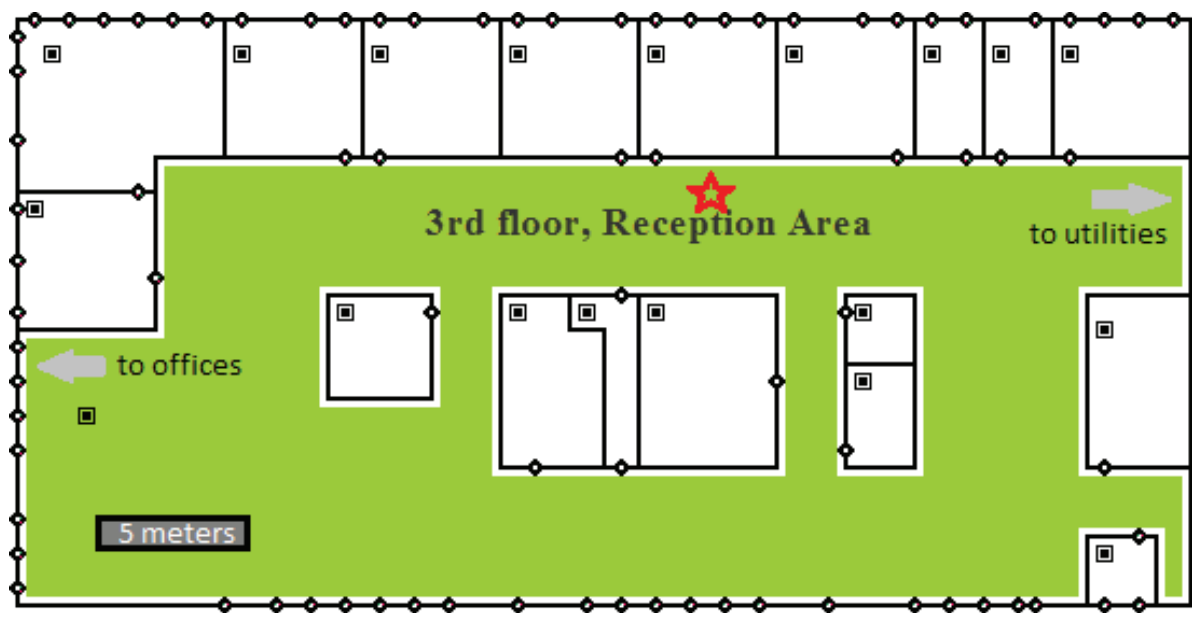

155 Figure 1: Building layout for the 3rd floor reception area (green area), where the indoor

156 sampling took place (marked with a red star), and the neighbouring rooms and offices (white 157 areas). 
160 precipitation and the average wind speed was $5.1 \mathrm{~m} \mathrm{~s}^{-1}$ with maximum being $\sim 15 \mathrm{~m} \mathrm{~s}^{-1}$. Hourly

161 meteorological data was collected for Hamad International Airport from the National Centres for

162 Environmental Information, National Oceanic and Atmospheric Administration, U.S. (Figure 2)

163 and wind was blowing mainly from NNW.

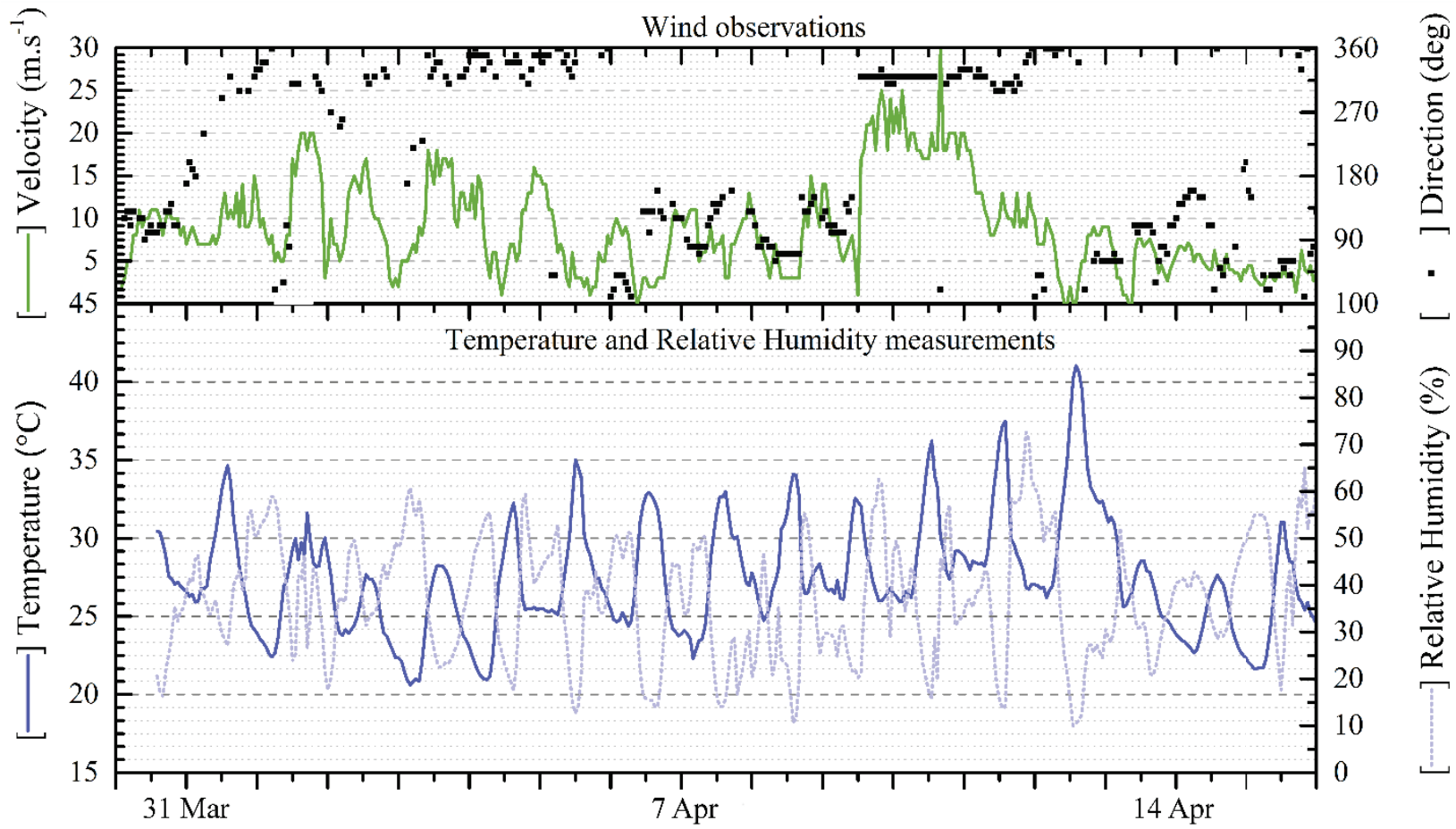

Figure 2: Temperature and relative humidity (\%) (own measurements) along with wind direction and velocity (from Hamad International Airport) for the study period (31-March to 16-April).

PM number concentrations, with one-minute resolution, were collected using two Environ

169 Check EDM 365, which is an air quality monitoring station manufactured by Grimm Aerosol

170 Technik GmbH \& Co. KG, Germany [42]. The measurement method is based on laser light

171 scattering. The monitoring station was used to measure both, particle number and mass

172 concentrations, over a size range of 0.25 up to $32 \mu \mathrm{m}$ in 31 size channels using a sampling rate of

$1731.2 \mathrm{~L} \mathrm{~min}^{-1}$. It produces particle mass concentrations $\left(\mu \mathrm{g} \mathrm{m}^{-3}\right)$ using a proprietary algorithm 
174 calibrated to the National Institute of Standards and Technology (NIST, USA) Arizona test dust.

175 According to vendor's certificate, measurements are equivalent to the European Standard EN 176 12341:2014 (superseding EN 14907:2005). Prior to the field campaign, a side-by-side inter-

177 comparison was conducted between the two monitoring stations for a week, which resulted in 178 standardized differences of less than $7 \%$ (i.e. the maximum of the distribution of the differences

179 was in all cases within the uncertainty limits of the calibration standards $\pm 3 \%$ ). In addition, the

180 correlation of the $\mathrm{PM}_{10}$ measurements performed by the two stations was checked through an 181 inter-comparison, for the same study period, against a reference gravimetric method according to 182 (European standard EN 12341:2104) using a low-volume sampler (LVS16 by GRIMM Aerosol 183 Technik GmbH \& Co.). The results show reasonable good agreement between the two methods

184 (Pearson correlation $\mathrm{r}=0.95$ with $\mathrm{p}$-value $<0.001$ ). More details about the employed gravimetric 185 method and protocols are provided by Saraga, et al. [43].

186

\subsection{Simulation tools}

Wind pressure is of high importance for the accurate calculation of the air infiltration rates.

189 It depends on the wind direction and speed, the urban airshed, the building heights and the local

190 terrain effects. Such input data can be loaded from CONTAM libraries, which contain

191 correlations of wind pressure profiles for low rise buildings [44]. However, these data express

192 average wind pressure coefficients for a simplified cubical building and do not consider the exact

193 building geometry.

194 To surpass this problem, the QUIC-CFD model is employed to compute the wind pressure 195 coefficients for the airflow paths, the point representing an opening on the building envelope, 196 required by CONTAM. The exact coordinates of these points are provided by CONTAM through 
the generation of the Path Location $\underline{\text { Data }}$ (PLD) file. QUIC calculates at each location point the

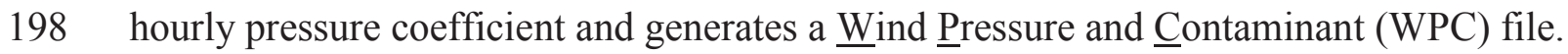
and pollutant transport in large buildings [38]. The overall outline of the numerical methodology 201 is presented in Figure 3.

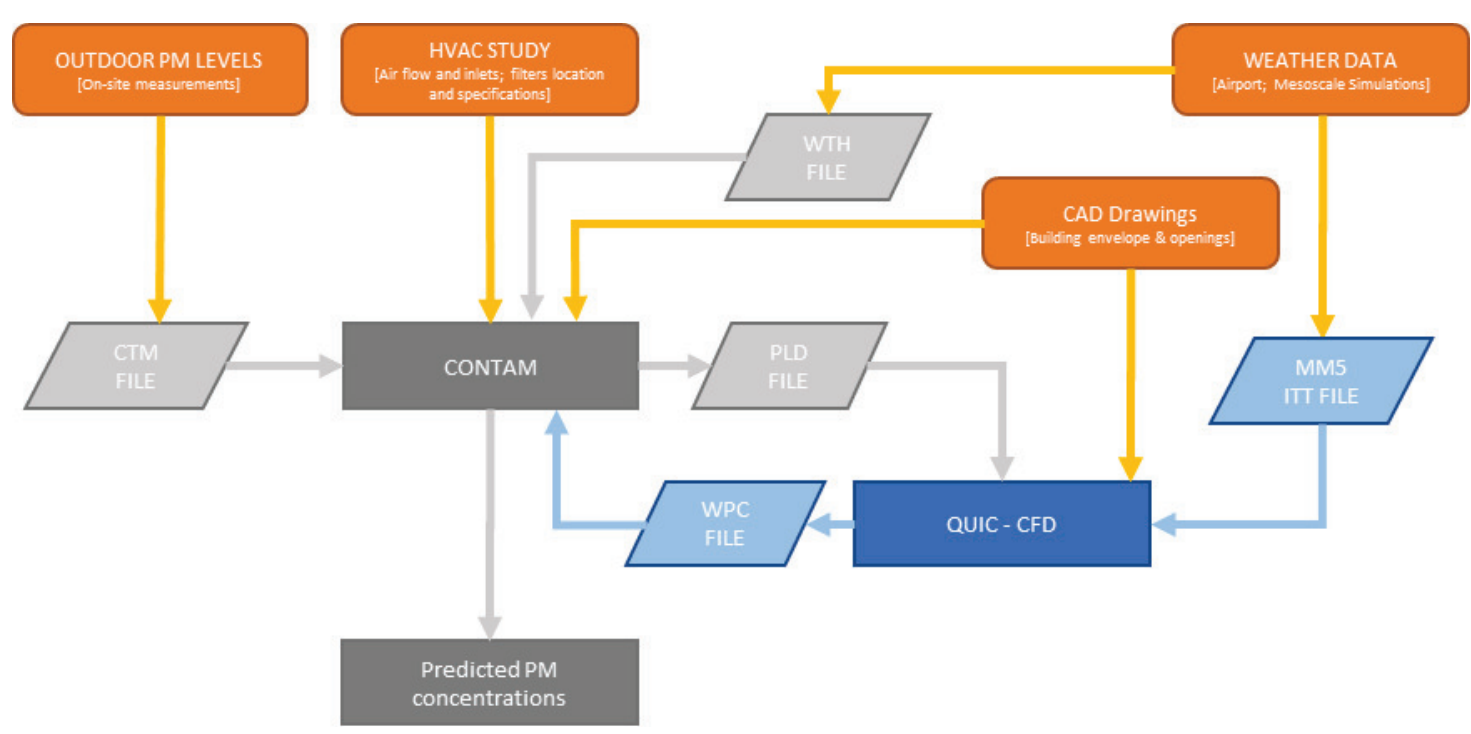

Figure 3: Outline of the developed numerical methodology.

\subsubsection{Building infiltration}

Over the last few decades, many models have been developed to study building infiltration

208 and indoor air quality (IAQ) for different types of buildings, such as COMIS and CONTAM [45].

209 The latter is one of the most widely used models [33], it is a multi-zone IAQ model appropriate

210 for the determination of (a) airflows and pressures, (b) contaminant concentrations, and (c)

211 personal exposure under different specified conditions.

Many researchers and engineers have used it for investigating indoor concentrations,

213 relative humidity and $\mathrm{PM}_{2.5}$ level concentrations $[46,47]$ in buildings, infiltration of ultra-fine 
214 particles [48] and recently PM level concentrations inside school bus [49]. Estimation impact of

215 the envelope air-tightening characteristics regarding the infiltration rates is one of the main

216 features of the model. The CONTAM airflow analysis is based on the initial algorithms

217 developed by Walton [50] for AIRNET computer program [51].

218 According to CONTAM, the transient partial differential equations for airflow analysis can

219 be written as follows [52]:

220

$$
\frac{\partial m_{i}}{\partial t}=\rho_{i} \frac{\partial V_{i}}{\partial t}+V_{i} \frac{\partial \rho_{i}}{\partial t}=\sum_{j} F_{j i}+F_{i}
$$

221 where $m_{i}$ is the mass of air for $i$ zone, $t$ is the time, $\rho_{i}$ is the density for $i$ zone, $V_{i}$ is the volume

222 for $i$ zone, $F_{i j}$ is the air flow rate from $j$ to $i$ zone and $F_{i}$ non-flow processes for $i$ zone (add or

223 remove significant quantities of air from $i$ zone). The $F_{i j}$ and $m_{i}$ are given by the following

224 equations:

$$
F_{i j}=f\left(P_{j}-P_{i}\right)
$$

where $P_{j}$ is the pressure for $j$ zone, $P_{i}$ is the pressure for $i$ zone, $f\left(P_{j}-P_{i}\right)$ is the function of the pressure drop along the flow path, $F_{i j}$ is the temperature for $i$ zone and $R$ is the ideal gas constant.

The flow of air through doors, windows gaps and cracks due to pressure difference is

231 defined as infiltration. In CONTAM, this phenomenon is governed by Bernoulli's equation [52].

$$
\Delta P=\left(P_{1}+\frac{\rho V_{1}^{2}}{2}\right)-\left(P_{2}+\frac{\rho V_{2}^{2}}{2}\right)+\rho g\left(z_{1}-z_{2}\right)
$$


where $\Delta P$ is the pressure drop between points 1 and $2, P_{1}$ is the inlet static pressure, $P_{2}$ is the

234 outlet static pressure, $g$ is the gravitational acceleration, $\rho$ is the air density, $z_{1}$ is the inlet

235 elevation and $z_{2}$ is the outlet elevation. The detailed indoor building geometry and information

236 about the HVAC system (inlets and hourly airflows schedule) and envelope openings (doors,

237 windows etc) were extracted from the building's HVAC study and the as-built drawings (CAD -

238 Computer Aided Design) (personal communication with the maintenance engineers).

The mass fractions of PM are solved after the flows have been computed, by simultaneous

240 solution of the non-symmetric, linear algebraic equations. More specifically, for each

241 contaminant species, CONTAM solves one transient conservation equation per control volume.

242 Herein, PM is the employed contaminant considered as non-trace, meaning that it does not affect

243 the density of air, and split into two $\left(\mathrm{PM}_{10-2.5}\right.$ and $\left.\mathrm{PM}_{2.5}\right)$ or three $\left(\mathrm{PM}_{10-2.5}, \mathrm{PM}_{2.5-1}, \mathrm{PM}_{1}\right)$ size

244 fractions depending on the scenario (see next section). Three additional processes are employed

245 to accurately simulate the PM behaviour i.e. filtration, deposition, and resuspension. The first

246 process is applied for all openings and HVAC filtration points (intake and discharge locations),

247 and the other two for all vertical and horizontal building elements (walls and floors). Filter

248 information has been extracted from the building HVAC study (personal communication) and the

249 deposition/resuspension parameters have been selected from the available CONTAM libraries to

250 match the building's materials. Each zone has been considered as an individual control volume.

251 Finally, outdoor concentration levels were provided by the field measurements, which are

252 imported into the CONTAM via the ambient contaminant (CTM) file. Similarly, the required

253 weather data for were prepared either as a simple tabular file or a CONTAM-compatible weather

254 (WTH) using real hourly data from the local meteorological authority. 


\subsubsection{Wind flow and pressure}

In this study, a CFD software known as QUIC was selected to calculate the external wind pressures during a dust storm event. During the past few years, the model has been validated and improved extensively by many scientists and engineers [53-55]. QUIC is comprised by three submodels, namely the QUIC-URB (3-D wind model), the QUIC-PLUME (Lagrangian dispersion model) and the QUIC-CFD model [34].

QUIC-URB is characterised as a 3-D empirical-diagnostic wind model which predicts the wind profiles around complex buildings by using empirical parameterizations and mass consistent techniques $[56,57]$.

QUIC-CFD model consists of the continuity and Navier-Stokes equations for 3-D turbulent fluid flow. The 3-D Reynolds-Averaged Navier-Stokes (RANS) equations are solved explicitly in time until a steady state is reached using a projection method [58]. All the governing equations can be written in the following general form known as transport equation for property $\phi$.

$$
\frac{\partial}{\partial t}(\rho \phi)+\operatorname{div}(\rho \mathbf{u} \phi)=\Gamma_{\phi} \operatorname{grad} \phi+S_{\phi}
$$

where $\rho$ is the density of the fluid, $\phi$ is the dependent variable (i.e. $u_{x}, u_{y}$ or $u_{z}$ for momentum, the variable $\phi$ also stands for the turbulence kinetic energy, or a turbulence length scale 1 for mass continuity), $\Gamma_{\phi}$ is the "effective" exchange coefficient of variable $\phi$, and $S_{\phi}$ is the source/sink term per unit volume, of variable $\phi$. The turbulence modelling is achieved by a simplified zero-equation model based on the Prandtl's mixing length model $[59,60]$. The continuity and RANS equations, along with the appropriate boundary conditions have been solved by means of the Finite Volume Method [61] on a staggered grid. For the discretisation of partial differential equations, a second-order central difference scheme in space and a second- 
order Adams-Bashforth scheme in time were selected, respectively, maintaining second-order accuracy in overall $[39,58]$.

For every hour in the study period a steady state simulation was conducted using mesoscale data for the initialization (generated with the MM5-Fifth-Generation Penn State/NCAR Mesoscale Model see [62] for details on the configuration and setup). The average roughness length for the bottom layer, representing the non-resolved ground and not the whole urban environment, was estimated to be equal to $0.2 \mathrm{~m}$ by imposing a logarithmic profile at the inlet boundary and matching the result with the mesoscale data. Also, a free slip boundary condition is applied at the rigid surfaces i.e. walls of the buildings. The top and side boundaries of the domain are handled by QUIC with no further requirements from the user. The 3-D computational domain for the simulations extends to $1000 \mathrm{~m}$ length (X), $1100 \mathrm{~m}$ width (Y) and $50 \mathrm{~m}$ height (Z). The first two dimensions are large enough to include the wider area and neighbouring buildings and they also follow related guidelines for CFD simulations in urban environments [63]. The third dimension has been set equal to the height of the first layer in MM5. A uniform Cartesian grid was also selected with $4 \mathrm{~m}$ resolution in $\mathrm{X}$ and $\mathrm{Y}$ directions and $1 \mathrm{~m}$ in $\mathrm{Z}$. The external building geometry was extracted from the above same CAD files as for CONTAM while dimensions for all other buildings, within the domain, have been extracted from Google Earth images. Overall configuration, e.g. boundary conditions, followed the instructions of QUIC literature [58].

\subsection{Investigated scenarios}

The selection of modelling scenarios for investigating the building infiltration of $\mathrm{PM}_{2.5}$ and $\mathrm{PM}_{10}$ involves the study of three different cases. The first one takes into account the filter specifications of the HVAC system of the commercial building on the simulation input parameters, as it is without fitting or calibration using only the available libraries of CONTAM 
software. The use of filters is to achieve efficient removal of particles from the HVAC system.

303 The filters specifications in the commercial building based on the American National $\underline{\text { Standard }}$ 304 Institute (ANSI)/ $\underline{\text { American }}$ Society of $\underline{H}$ eating, Refrigeration, and $\underline{\text { Air-Conditioning Engineers }}$ 305 (ASHRAE) Standard 52.2 Minimum Efficiency Reporting ㅌalue (MERV) 14. According to 306 MERV 14, the filter \% efficiency $(E)$ for PM at Range $1(0.3-1.0 \mu \mathrm{m})$ is $75 \leq \mathrm{E}_{1} \leq 85$, at Range 2 $307(1.0-3.0 \mu \mathrm{m})$ is $E_{2} \geq 90$ and at Range $3(3.0-10.0 \mu \mathrm{m})$ is $E_{3} \geq 95$. The filtering efficiency is a very 308 important parameter for the building simulation in order to identify the size and distribution of 309 the outdoor particles from the mechanical ventilation system to the building.

311 the measured data only for the non-operational hours of the first day of the study period.

312 Coincidentally, this was the day prior to the dust storm event. More specifically, CONTAM and 313 QUIC, coupled as described earlier, were employed to calculate the hourly $\mathrm{PM}_{10}$ (transformed to $314 \mathrm{PM}_{2.5-10}$ ) and $\mathrm{PM}_{2.5}$ indoor concentration levels from March $31^{\text {st }} 15: 00$ to April $1^{\text {st }}$ 05:00 without considering any PM removal from the HVAC filters (e.g. filters' efficiency set to $0 \%$ ). Using the

316 linear least squares method the best fitting coefficients (slope) were obtained through the

317 calculated and measured concentrations, assuming that these coefficients represent the filters'

318 efficiencies for the $\mathrm{PM}_{2.5-10}$ and $\mathrm{PM}_{2.5}$ respectively. The obtained fitted filters' efficiencies were $31998.2 \%$ and $98 \%$ for the $\mathrm{PM}_{2.5-10}( \pm 0.5 \%)$ and $\mathrm{PM}_{2.5}( \pm 1.0 \%)$, respectively. They are relatively 320 higher than the nominal ones (according to MERV 14), which could be attributed to the larger 321 loads of PM and the subsequent formation of a thicker and denser filter cake during operation. Finally, the third scenario involves the calculation of PM levels based on the HVAC operation "off" i.e. the HVAC system does not operate. Table 1 presents the considered scenarios. 
All simulations with CONTAM had very short computational times, less than a few minutes. The QUIC simulations lasted around nine hours for the whole study period and were executed at the Texas A\&M University at Qatar High Performance Computing Facility (Cray®) XC40-AC) using eight CPU cores (Intel Xeon E5-2690 V3).

Table 1: The considered scenarios with the varying input parameters.

\begin{tabular}{llc}
\hline Name & Filter \% efficiency for PM & HVAC \\
& {$[$ Based on ASHRAE Standard 52.2] } & \\
\hline & $\mathrm{PM}_{3-10} \geq 95$ & On \\
MERV14 - HVAC ON & $\mathrm{PM}_{1-3} \geq 90$ & \\
& $75 \leq \mathrm{PM}_{0.3-1} \leq 85$ & \\
& {$\left[\mathrm{Based}^{2}\right.$ own estimations/fitting $]$} & \\
FIT-HVAC ON & $\mathrm{PM}_{2.5-10}=98.2$ & On \\
HVAC OFF & $\mathrm{PM}_{2.5}=98$ & \\
\hline
\end{tabular}

\section{RESULTS AND DISCUSSION}

\subsection{Field measurement analysis}

Figure $4 \mathrm{a}$ exhibits the time series of the outdoor and indoor $\mathrm{PM}_{2.5}$ and $\mathrm{PM}_{10}$ mass concentration levels between 30/03/2015 and 16/04/2015. In general, the outdoor $\mathrm{PM}_{10}$ varied from $55 \mu \mathrm{g} \mathrm{m}^{-3}$ to over $30,000 \mu \mathrm{g} \mathrm{m}^{-3}$, while outdoor $\mathrm{PM}_{2.5}$ from $30 \mu \mathrm{g} \mathrm{m}^{-3}$ to $5,550 \mu \mathrm{g} \mathrm{m}^{-3}$. On

336 the other hand, the indoor $\mathrm{PM}_{10}$ measurements were found to be in the range of 1-700 $\mu \mathrm{g} \mathrm{m}^{-3}$, 337 while indoor $\mathrm{PM}_{2.5}$ between 0.4 and $180 \mu \mathrm{g} \mathrm{m}^{-3}$. Although, the outdoor $\mathrm{PM}_{2.5}$ and $\mathrm{PM}_{10}$ levels varied significantly during the measurement period, the minimum values were always above the

$339 \mathrm{PM}_{10}$ Qatar National Ambient Air Quality Standards $\left(150 \mu \mathrm{g} \mathrm{m}{ }^{-3}\right.$ daily average). Indoor $\mathrm{PM}_{2.5}$

340 and $\mathrm{PM}_{10}$ concentration values are lower and affected only during severe outdoor conditions. It is

341 also observed that the hourly variation of the indoor PM is driven by the pattern of the outdoor 

envelope.

(a)

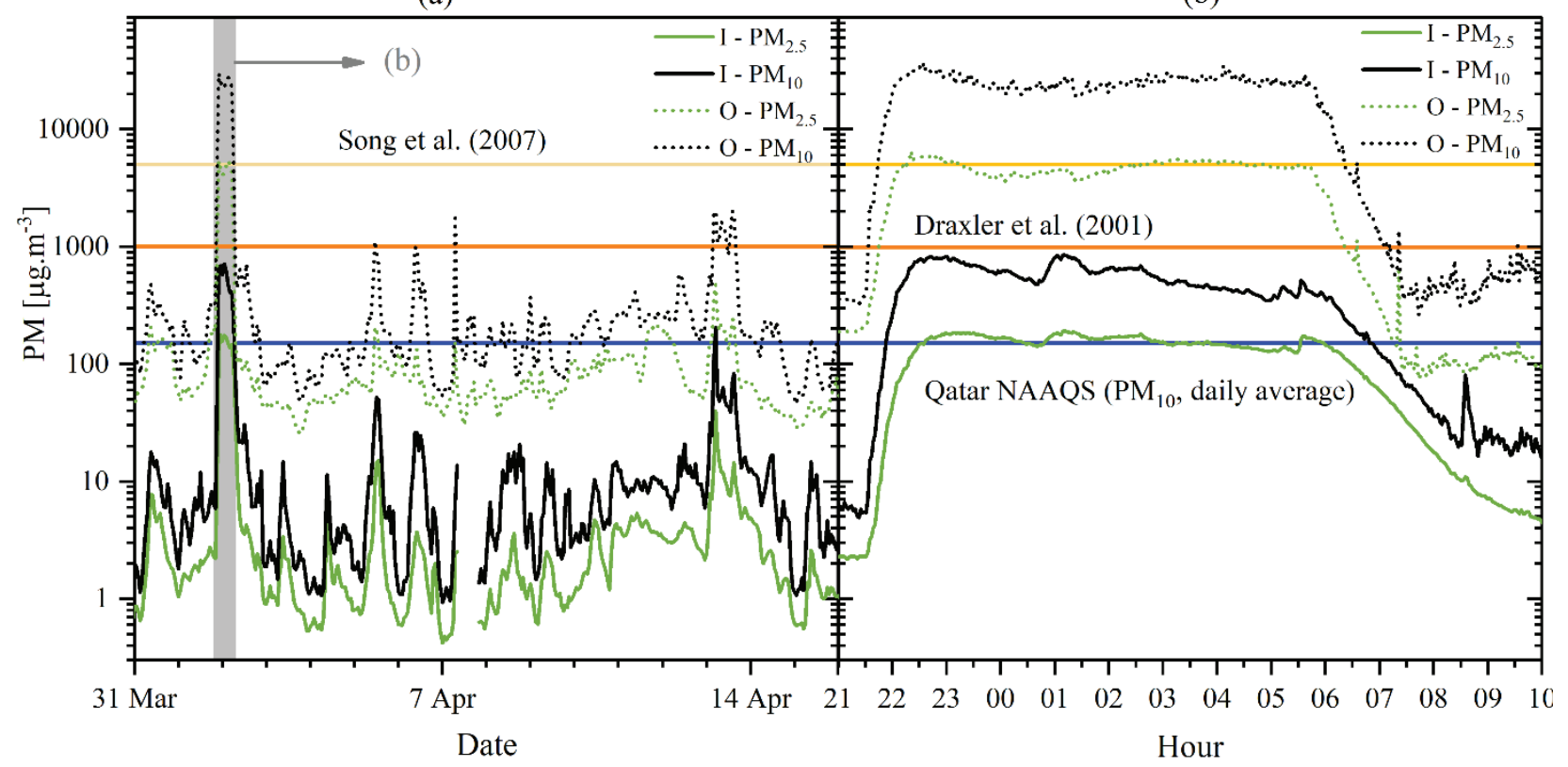

344

Figure 4. Outdoor and indoor PM concentrations for the a) whole study period (hourly averages) and b) dust storm event (1-min averages). The yellow and orange solid lines represent the proposed severe dust storm threshold levels according to the classification of Song, et al. [17] and Draxler, et al. [64]. The blue solid line at $150 \mu \mathrm{g} \mathrm{m}^{-3}$ presents the Qatar National Air Quality Standard (AQS) for $P M_{10}$ (daily average). The light grey shaded area represents the time period of the selected severe dust storm event.

Figure $4 \mathrm{~b}$ shows the minute values for outdoor and indoor $\mathrm{PM}_{2.5}$ and $\mathrm{PM}_{10}$ levels from 21:00h April $1^{\text {st }}$ until 10:00h. Note that after 14:00h, the building is closed for the public and most occupants have left until 16:00. This means that the building doors were practically closed but PM infiltrated almost immediately. The PM mass concentration levels remained at the highest values for almost 8 hours. Then, they decayed rapidly to normal for the region levels. The indoor 
PM mass concentrations decrease twice as slower than the outdoor which is attributed to the characteristic behaviour of the isolated building envelope.

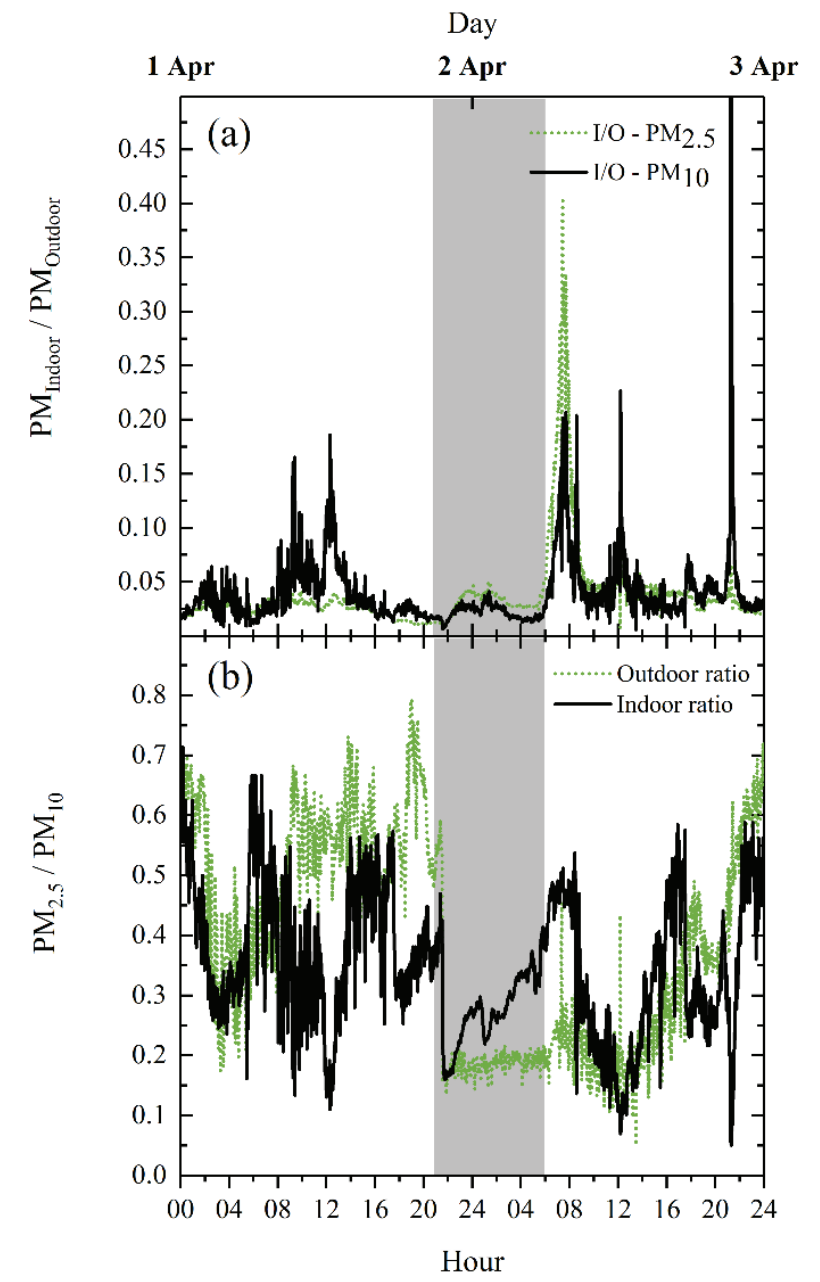

Figure 5: Before, during and after the dust storm event: (a) I/O-PM 2.5 and $I / O-P M_{10}$, and (b) indoor and outdoor ratio of $P M_{2.5} / P M_{10}$, respectively. The light grey shaded area represents the time period of the severe dust storm event.

To demonstrate better this effect, in Figure 5a, the temporal evolution of indoor to outdoor

363 ratio is presented. The ratio is constant throughout the initiation and duration of the dust storm

364 event (see grey shaded area). However, the ratios do not follow the decay of the event, as it takes

365 around 4 hours to reach back to the normal levels ( $\sim 0.03)$. Probably, this would have been even 
longer if the building remained closed the next day (operation hours start around 08:00 am in the

367 morning). It is also noticed that the $\mathrm{I} / \mathrm{O}$ ratio for both the $\mathrm{PM}_{2.5}$ and $\mathrm{PM}_{10}$ displays low values

368 before the initiation of the dust storm event which is associated with the filtration and tightness of

369 the building and thus significantly lower than past studies focusing on residential buildings [31].

370 Furthermore, the normal $\mathrm{I} / \mathrm{O}$ ratios of $\mathrm{PM}_{10}$ are little higher than those of $\mathrm{PM}_{2.5}$, as seen before

371 and after the dust event, excluding few periods, as shown in Figure 5a.

372 Figure 5b exhibits the ratios of $\mathrm{PM}_{2.5} / \mathrm{PM}_{10}$ before, during, and after the severe dust storm

373 period. It is seen that before and after the event there are not great differences between the

374 outdoor and indoor ratios. On the onset of the severe dust storm event around 21:00 we notice a

375 rapid decrease of both the outdoor and indoor ratios. The former is characteristic of large dust

376 storms that are usually dominated by larger particles. The latter, indicates the start of infiltration

377 process in the building. However, the indoor ratio is progressively increasing during the event

378 until the opening of the building $(08: 00 \mathrm{~h})$ thereafter it follows the outdoor ratio. This behaviour

379 can be explained by a) the higher deposition rates of the larger particles and their subsequent

380 removal from the atmosphere, and b) the higher infiltration of smaller particles. The data

381 collected in this study are not enough to identify the contribution of each mechanism, with some

382 reservations, we propose (a) as a more prominent mechanism compared to (b), based on

383 interpretation of the four ratios (Figure 5) and measured concentration levels (Figure 4).

\subsection{Prediction of indoor PM mass concentrations}

In this study, the indoor $\mathrm{PM}_{2.5}$ and $\mathrm{PM}_{10}$ were calculated for three different scenarios

387 (Section 2.3). 
Figure 6 presents the collected measurements for $\mathrm{PM}_{2.5}$ from $30 / 3 / 2015$ to $16 / 04 / 2015$, together with the predicted $\mathrm{PM}_{2.5}$ values according to the considered scenarios; the light gray shaded area identifies the period of the severe dust storm event.

It is observed that the predicted and measured values of indoor $\mathrm{PM}_{2.5}$ follow a relatively similar pattern, excluding the case for HVAC operation "off". The predicted $\mathrm{PM}_{2.5}$ values for scenario "MERV14-HVAC ON" tend to overestimate the measured values for $\mathrm{PM}_{2.5}$, while the "FIT-HVAC ON" model seems to approach much better the measured $\mathrm{PM}_{2.5}$ levels. Again, this is supported from Figure 6a-b which illustrates the highest peaks of the measured $\mathrm{PM}_{2.5}$ levels along with the predicted values for the three developed models during the severe dust storm event, indicating the performance (overestimation or underestimation) of the models. It is clear 398 that the performance of FIT-HVAC ON scenario (max predicted $\sim 200 \mu \mathrm{g} . \mathrm{m}^{-3}$ vs. max measured $399180 \mu \mathrm{g} . \mathrm{m}^{-3}$ ) is much better than "MERV14-HVAC ON" scenario (max predicted $~ 550 \mu \mathrm{g} . \mathrm{m}^{-3}$ vs. max measured $\left.180 \mu \mathrm{g} \cdot \mathrm{m}^{-3}\right)$, especially during the period $(\sim 22: 00-06: 00 \mathrm{~h})$ when the levels of $\mathrm{PM}_{2.5}$ concentrations reach the highest values. It is also seen that the two models with HVAC operation "on" provide insights not only during the main dust storm event, but also for normal days and secondary storm events (e.g. on 13 April 2015, see Figure 6a-b).

In the case of HVAC operation "off", the predicted $\mathrm{PM}_{2.5}$ values initially increase but not to the level of the measured $\mathrm{PM}_{2.5}$. In this scenario, PM infiltrate only via the building's and windows' cracks. Furthermore, after the end of the severe dust storm event the $\mathrm{PM}_{2.5}$ levels remain stable because there is no ventilation to refresh the indoor air, as shown in Figure $\mathbf{6 b}$. In addition, neither model can capture the much lower concentrations during the closed-

409 office hours, whatsoever just a few $\mu \mathrm{g} \cdot \mathrm{m}^{-3}$ lower. Specifically, a $3.9 \mu \mathrm{g} \cdot \mathrm{m}^{-3}$ and $2.8 \mu \mathrm{g} \cdot \mathrm{m}^{-3}$ 410 relative and absolute deviation was estimated for the "MERV14-HVAC ON" and $0.9 \mu \mathrm{g} \cdot \mathrm{m}^{-3}$ and $4110.6 \mu \mathrm{g} \cdot \mathrm{m}^{-3}$, respectively, for the "FIT-HVAC ON". These differences between the predicted and 
412 measured $\mathrm{PM}_{2.5}$ could be attributed to the models' assumptions and also to the measurements

413 uncertainty of the experimental instruments.

(a)

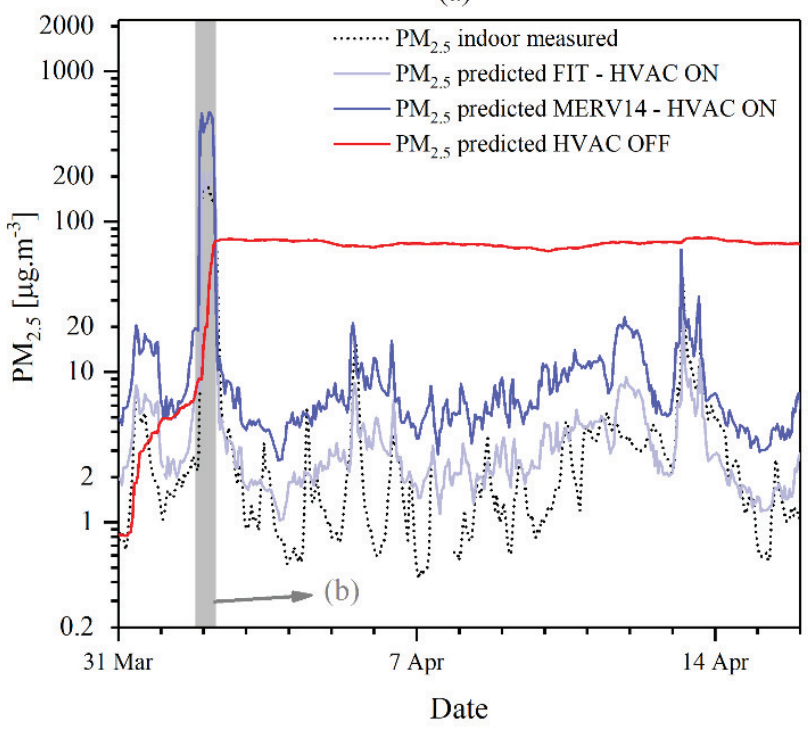

(c)

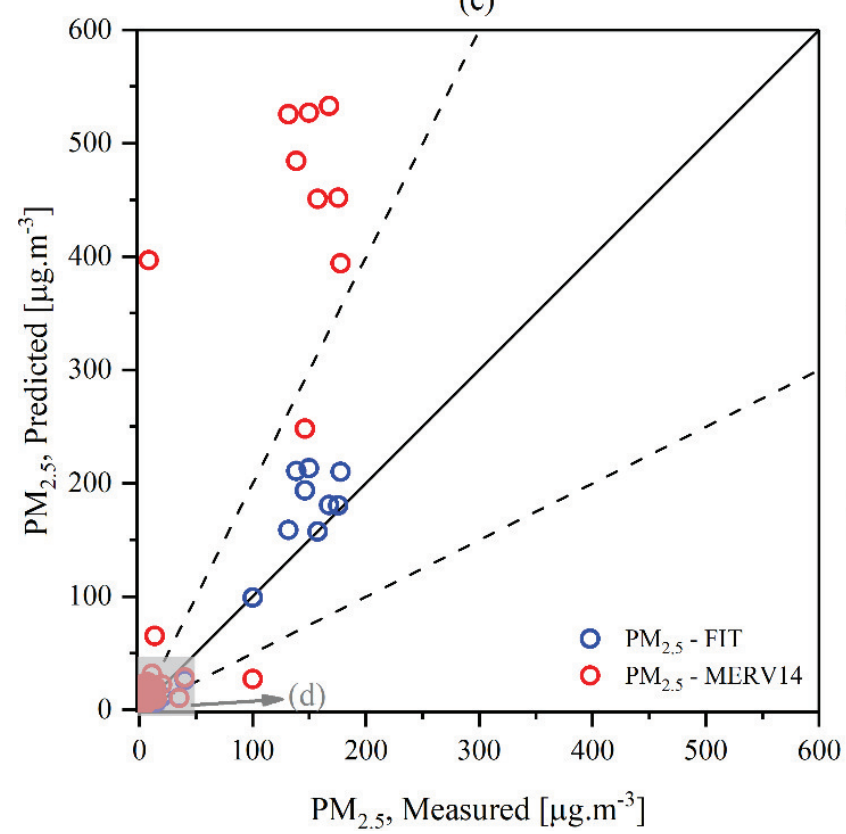

(b)

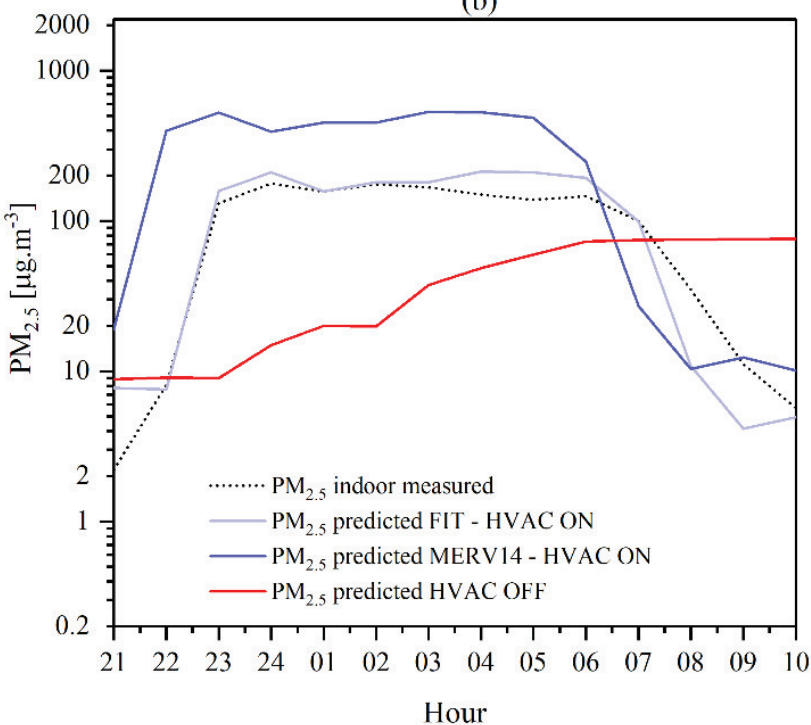

(d)

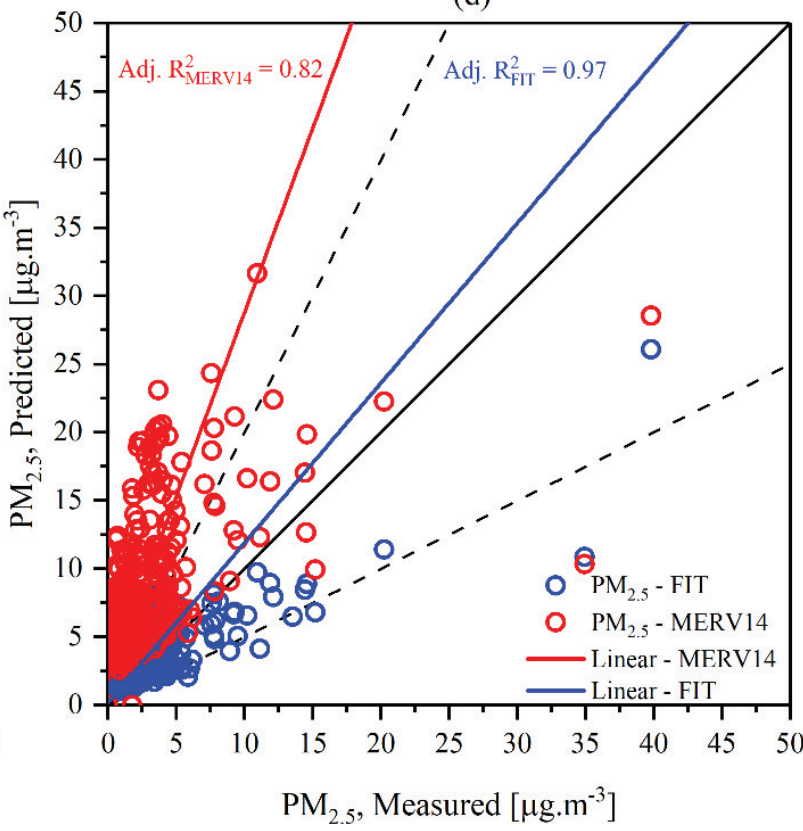

416 Figure 6: Comparison of indoor measured and predicted $P M_{2.5}$ levels for a) all the collected data

417 and b) the dust storm period. Also, the scatter plots of measured versus predicted mass

418 concentration c) in full graph scale and d) zoom graph scale including the additional linear 
fitting for FIT (red solid line) and MERV14 (blue solid line) scenarios. The black solid line indicates perfect agreement, while the black dashed lines represent the fraction of predictions within a factor of two of measurements (FAC2). The light grey shaded areas represent in (a) the period of the selected dust event and in (c) the zoom area.

Figure 7 depicts the collected measurements for the $\mathrm{PM}_{10}$ concentration levels (30/3/2015 $16 / 04 / 2015)$ along with the predictions obtained from the three selected numerical scenarios. The light gray shaded area presents from start to finish the severe dust storm event. It is seen that the predicted $\mathrm{PM}_{10}$ values follow relatively similar motif to measured $\mathrm{PM}_{10}$, except for the case at which the HVAC system operation is "off". It is also observed that in a few cases the predicted $\mathrm{PM}_{10}$ concentration levels are also approaching or matching the measured $\mathrm{PM}_{10}$. HVAC ON" scenario almost match the measured $\mathrm{PM}_{10}$ levels at 22:00 and 01:00, while for the 431 high peak period of $\mathrm{PM}_{10}\left(21: 30\right.$ - 05:30) the specific model overestimates the measured $\mathrm{PM}_{10}$. 432 In the case of "MERV14 - HVAC ON", the model overestimates the measured $\mathrm{PM}_{10}$ during the high peak period but approaches well at the end of the severe dust storm event. in Figure 6c-d. It is noticed that the measured and predicted $\mathrm{PM}_{2.5}$ levels are highly correlated with an adjusted $\mathrm{R}^{2}$ equal to 0.82 for "Linear - MERV14" and 0.97 for "Linear - FIT" scenarios,

437 respectively, as shown in Figure 6d. It is clear that the estimated $\mathrm{PM}_{2.5}$ concentrations are in 438 good agreement with the measurements, while the performance of " $\mathrm{PM}_{2.5}-\mathrm{FIT}$ " model is better 439 than $\mathrm{PM}_{2.5}-$ MERV14 model. Subsequently, the most concentration values of $\mathrm{PM}_{2.5}$ mainly fall 440 within FAC2 (Factor of two), which also constitutes a common metric for the performance of 441 atmospheric dispersion models. 
(a)

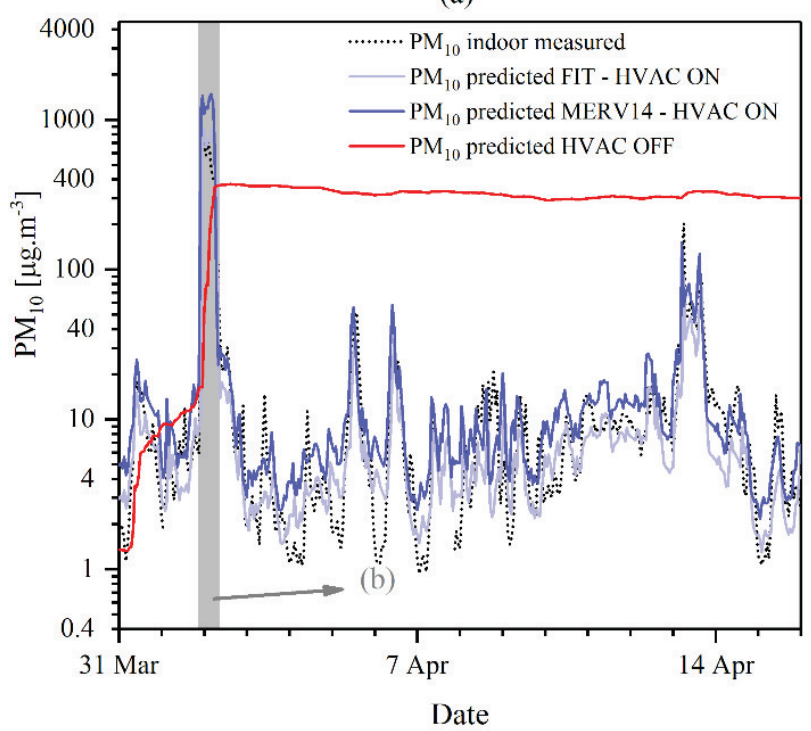

(c)

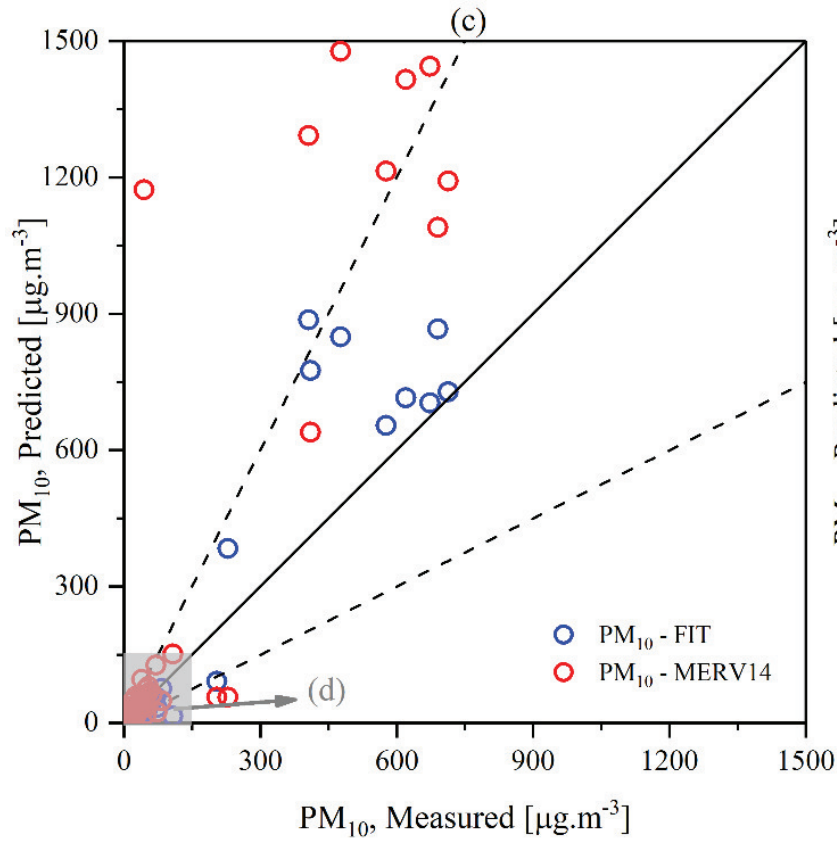

(b)

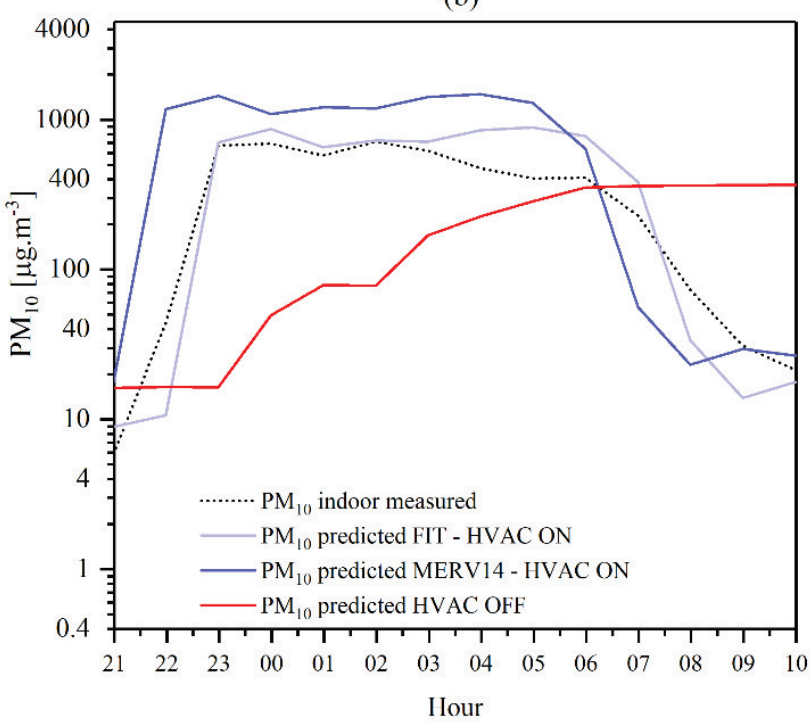

(d)

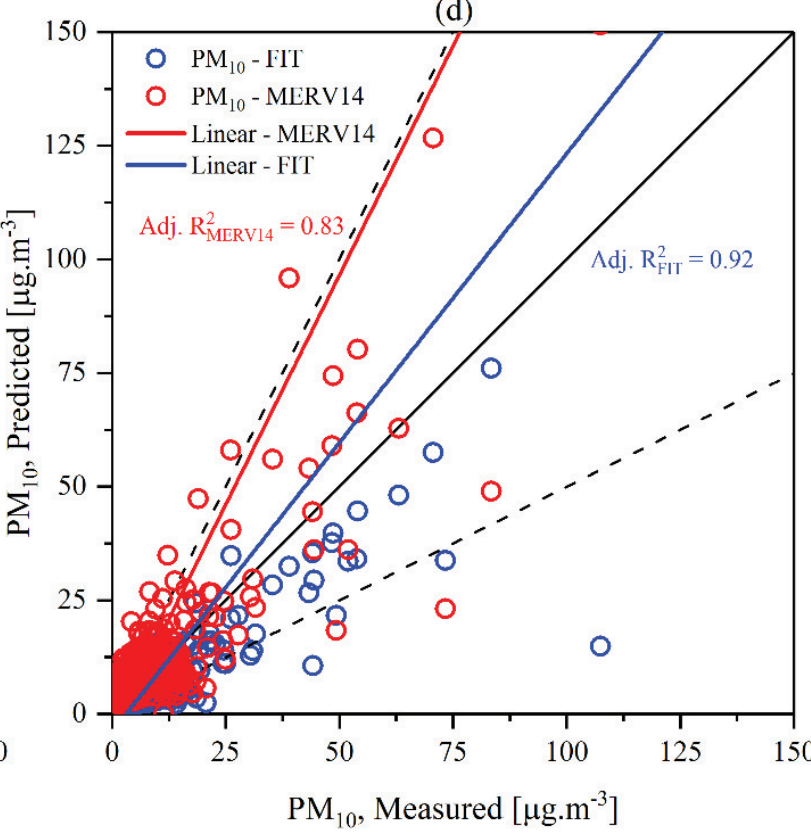

Figure 7: Comparison of indoor measured and predicted $P M_{10}$ levels for a) all the collected data

445 and b) the dust storm period. Also, the scatter plots of measured versus predicted mass

446 concentration c) in full graph scale and d) zoom graph scale including the additional linear

447 fitting for FIT (red solid line) and MERV14 (blue solid line) scenarios. The black solid line

448 indicates perfect agreement, while the black dashed lines represent the fraction of predictions 
within a factor of two of measurements (FAC2). The light grey shaded areas represent in (a) the period of the selected dust event and in (c) the zoom area. performance is observed for " $\mathrm{PM}_{10}-$ FIT" model with an adjusted $\mathrm{R}^{2}$ equal to 0.92 , while for $\mathrm{PM}_{2.5}$ - MERV14 model a value of 0.83 is obtained. It is concluded that the predicted $\mathrm{PM}_{10}$ levels for both models are in fair agreement with the measured $\mathrm{PM}_{10}$ concentration, giving some confidence for the accuracy of the present numerical methodology.

\subsection{Qualitative analysis of the meteorological conditions impact}

Previous paragraphs presented and discussed the field measurement data and the modelling calculations focusing on the observed levels and ratios for the $\mathrm{I} / \mathrm{O}$ levels and for $\mathrm{PM}_{2.5} / \mathrm{PM}_{10}$. The qualitative discussion of how the outdoor meteorological conditions affect the PM infiltration and ratios can also lead to interesting hypothesis. Figure $\mathbf{8}$ presents the polar plots of the dependence of these two ratios (PM2.5 / PM10 and I/O) on the wind direction and velocity. In Figure 8a is noted that the outdoor $\mathrm{PM}_{2.5} / \mathrm{PM}_{10}$ ratio tends to be larger at low wind speeds but not at calm conditions (typically less than $1 \mathrm{~m} \cdot \mathrm{s}^{-1}$ ), and mainly from two specific wind segments West and East. These segments match somehow the direction of the coastline and of two trafficked streets

466 but not exactly (building orientation NNW to SSE). The indoor $\mathrm{PM}_{2.5} / \mathrm{PM}_{10}$ ratio (Figure 8b) 467 increases when both the outdoor ratio and wind velocity are high. The $\mathrm{PM}_{10} \mathrm{I} / \mathrm{O}$ ratio (Figure 8c) 468 does not reveal any pattern. On the contrary, the $\mathrm{PM}_{2.5} \mathrm{I} / \mathrm{O}$ (Figure 8d) shows a very distinct 469 pattern for the strong North and South winds. Based solely on this figure, a frivolous conclusion 470 could have been that there is a strong correlation of the $\mathrm{PM}_{2.5} \mathrm{I} / \mathrm{O}$ ratio with the wind velocity. 471 However, examining Figure 8a and $\mathrm{d}$ it is clear that the $\mathrm{PM}_{2.5} \mathrm{I} / \mathrm{O}$ increase during these periods it 
472 is driven by the outdoor $\mathrm{PM}_{2.5} / \mathrm{PM}_{10}$ decrease. Indeed, a correlation analysis including all the

473 above ratios and the wind velocity revealed no identifiable correlation among them (figure or

474 detailed results not shown here).

475

(a)

(b)

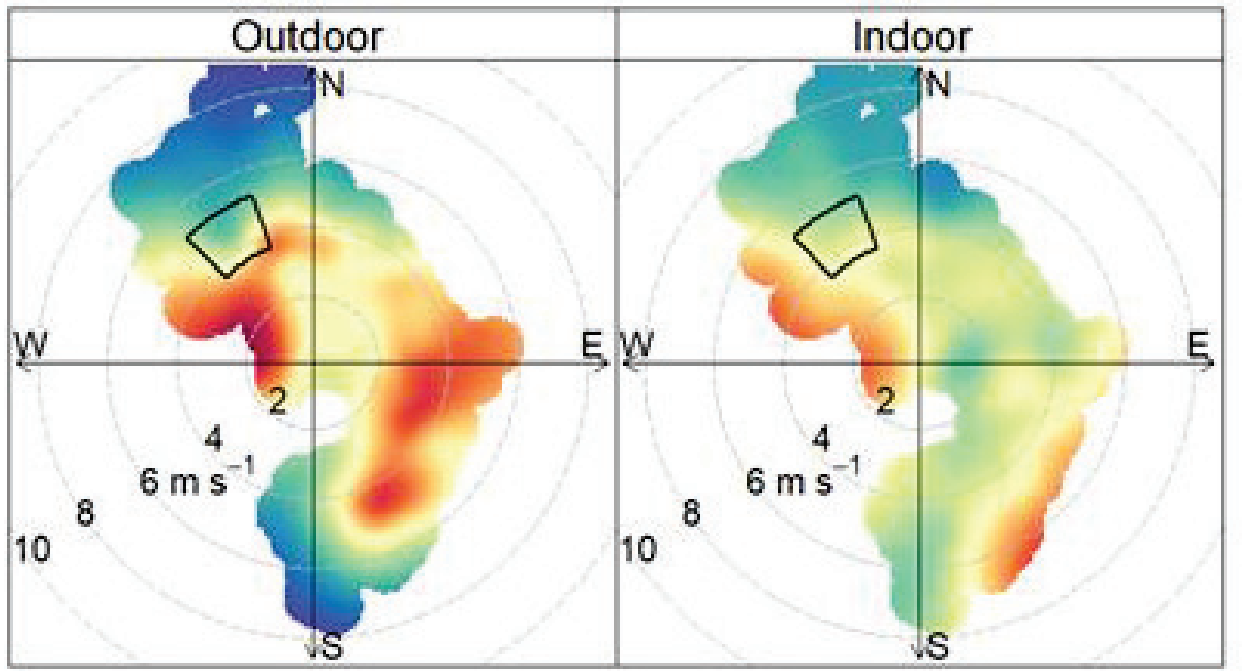

mean

0.6

0.5

0.4

0.3

0.2

(c)

(d)

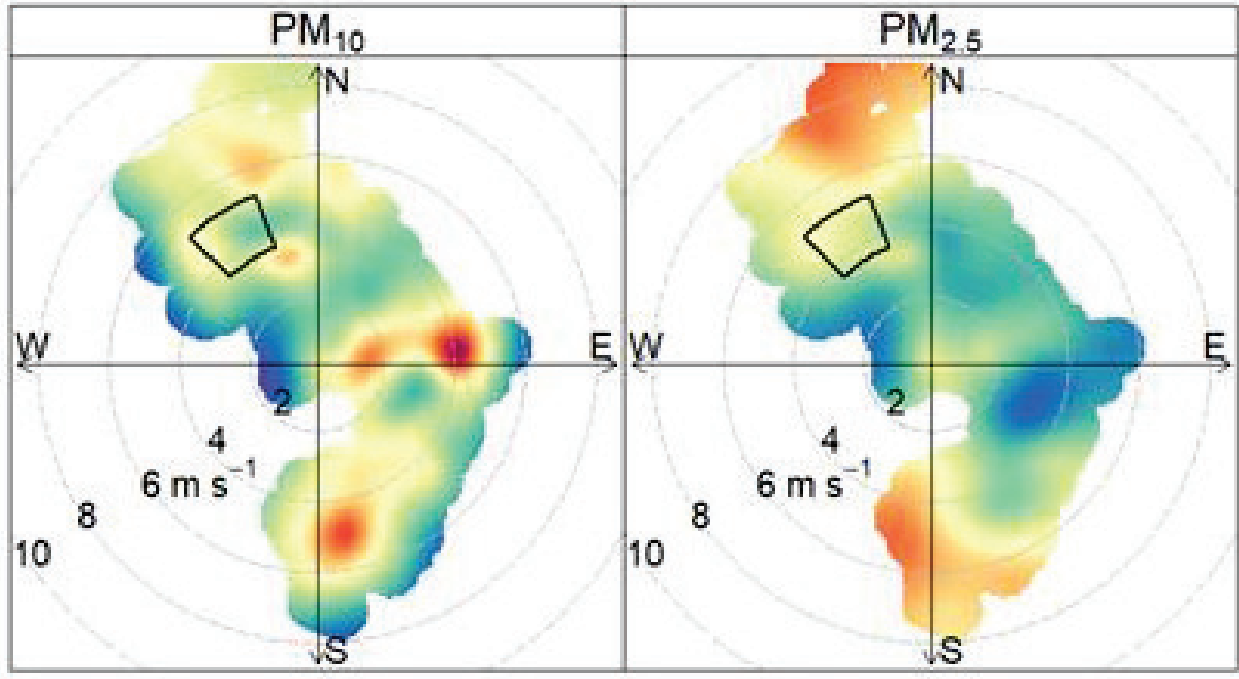

mean

0.07

0.06

0.05

0.04

0.03

0.02

I/O

476 
477 Figure 8: Polar plots displaying the dependence of $P M_{2.5} / P M_{10}$ and I/O ratios on the wind 478 direction and velocity for the whole study period. The arc segment encloses the observed conditions during the severe dust event.

\section{CONCLUSIONS}

Dust storm events are common natural phenomena of dry and arid climates that severely affect human life and infrastructure. This study presented the measurements of an experimental campaign that captured one of the most severe such events in Middle East of the past decade and its impact to indoor air quality at a typical office-building. Infiltration of PM during the dust event was almost immediate for both $\mathrm{PM}_{10}$ and $\mathrm{PM}_{2.5}$. After the event, cleaning of the indoor air was slow when HVAC was the only mechanism but it accelerated when the building doors opened. Ratios of indoor and outdoor, and $\mathrm{PM}_{2.5}$ and $\mathrm{PM}_{10}$ levels showed interesting patterns. For example, outdoor $\mathrm{PM}_{2.5} / \mathrm{PM}_{10}$ was around 0.2 during the event but the indoor ratio started from this value and progressively increased owe to $\mathrm{PM}_{10}$ deposition. Overall, outdoor levels during normal and event days where mostly above WHO and Qatar National Air Quality standards, but not the indoor levels.

A combination of modelling tools was presented for predicting the airborne PM building 495 infiltration during severe dust storm events and normal days. The numerical results present 496 encouraging agreement with measurements when standard HVAC information is employed, 497 using the CONTAM libraries. The agreement is improved when more representative information 498 for the HVAC filters is available i.e. by obtaining specific PM removal filter efficiencies using 499 measured data. Finally, it is important to note that future studies are required to capture more 
500 similar events, study the infiltration at residential buildings, and assess the available mitigation

501 strategies against dust events.

502

503

\section{ACKNOWLEDGMENTS}

504 This publication was made possible by a NPRP award [NPRP 7-649-2-241] from the Qatar 505 National Research Fund (a member of The Qatar Foundation). The authors would also like to 506 acknowledge the assistance from the Ministry of Public Health, State of Qatar. The High507 Performance Computing resources and services used in this work were provided by the IT 508 Research Computing group in Texas A\&M University at Qatar. The statements made herein are 509 solely the responsibility of the authors.

\section{CONFLICT OF INTEREST STATEMENT}

512 The authors declare no competing interests.

\section{REFERENCES}

515 [1] A.S. Goudie, Desert dust and human health disorders, Environ. Int. 63 (2014) 101-113.

516 [2] D.A. Gillette, J. Adams, D. Muhs, R. Kihl, Threshold friction velocities and rupture moduli 517 for crusted desert soils for the input of soil particles into the air, Journal of Geophysical 518 Research: Oceans 87 (1982) 9003-9015.

519 [3] A.S. Goudie, N.J. Middleton, Saharan dust storms: nature and consequences, Earth Sci. Rev. $520 \quad 56(1-4)(2001) 179-204$.

521 [4] L.J. Sutton, Haboobs, Quarterly Journal of the Royal Meteorological Society 51(213) (1925) 25-30. 
[5] D.A. Membery, A gravity-wave Haboob?, Weather 40(7) (1985) 214-221.

524 [6] S.D. Miller, A.P. Kuciauskas, M. Liu, Q. Ji, J.S. Reid, D.W. Breed, A.L. Walker, A.A. 525 Mandoos, Haboob dust storms of the southern Arabian Peninsula, Journal of Geophysical 526 Research: Atmospheres 113 (2008) D01202.

527 [7] A.H. Bu-Olayan, B.V. Thomas, Dispersion model on PM 2.5 fugitive dust and trace metals 528 levels in Kuwait governorates, Environ. Monit. Assess. 184(3) (2012) 1731-1737.

529 [8] C.A.I. Pope , M. Ezzati , D.W. Dockery Fine-Particulate Air Pollution and Life Expectancy in 530 the United States, N. Engl. J. Med. 360(4) (2009) 376-386.

531 [9] Z.H. Yang, Association of inhalable particles in dust events with daily outpatient visits for 532 Tracheitis, J. Environ. Occup. Med. 30 (2013) 88-92.

533 [10] A. Vodonos, M. Friger, I. Katra, L. Avnon, H. Krasnov, P. Koutrakis, J. Schwartz, O. Lior, 534 V. Novack, The impact of desert dust exposures on hospitalizations due to exacerbation of 535 chronic obstructive pulmonary disease, Air Qual. Atmos. Health 7(4) (2014) 433-439.

536 [11] A. Vodonos, M. Friger, I. Katra, H. Krasnov, D. Zahger, J. Schwartz, V. Novack, Individual 537 effect modifiers of dust exposure effect on cardiovascular morbidity, Plos One 10(9) (2015) $538 \mathrm{e} 0137714$.

539 [12] N. Martinelli, O. Olivieri, D. Girelli, Air particulate matter and cardiovascular disease: A 540 narrative review, European journal of internal medicine 24(4) (2013) 295-302.

541 [13] K. Onishi, S. Otani, A. Yoshida, H. Mu, Y. Kurozawa, Adverse health effects of Asian dust 542 particles and heavy metals in Japan, Asia-Pacific Journal of Public Health 27(2) (2015) NP1719$543 \quad$ NP1726.

544 [14] F.D. Longueville, Y.-C. Hountondji, S. Henry, P. Ozer, What do we know about effects of 545 desert dust on air quality and human health in West Africa compared to other regions?, Sci. Total 546 Environ. 409(1) (2010) 1-8. 
[15] A.N. Al-Dabbous, P. Kumar, Source apportionment of airborne nanoparticles in a Middle

548 Eastern city using positive matrix factorization, Environmental Sciences: Processes and Impacts $549 \quad 17(4)(2015) 802-812$.

550 [16] V. Tsiouri, K.E. Kakosimos, P. Kumar, Concentrations, sources and exposure risks 551 associated with particulate matter in the Middle East Area—a review, Air Quality, Atmosphere \& 552 Health 8(1) (2014) 67-80.

553 [17] Z. Song, J. Wang, S. Wang, Quantitative classification of northeast Asian dust events, 554 Journal of Geophysical Research: Atmospheres 112 (2007) D04211.

555 [18] S.-J. Chen, L.-T. Hsieh, M.-J. Kao, W.-Y. Lin, K.-L. Huang, C.-C. Lin, Characteristics of 556 particles sampled in southern Taiwan during the Asian dust storm periods in 2000 and 2001, 557 Atmos. Environ. 38(35) (2004) 5925-5934.

558 [19] H. Krasnov, I. Katra, P. Koutrakis, M.D. Friger, Contribution of dust storms to PM10 levels 559 in an urban arid environment, J. Air Waste Manage. Assoc. 64 (2014) 89-94.

560 [20] C. Mitsakou, G. Kallos, N. Papantoniou, C. Spyrou, S. Solomos, M. Astitha, C. Housiadas, 561 Saharan dust levels in Greece and received inhalation doses, Atmos. Chem. Phys. 8(23) (2008) $562 \quad 7181-7192$.

563 [21] R.A. Abbass, P. Kumar, A. El-Gendy, An overview of monitoring and reduction strategies 564 for health and climate change related emissions in the Middle East and North Africa region, 565 Atmos. Environ. 175 (2018) 33-43.

566 [22] C.D. Argyropoulos, A.M. Ashraf, N.C. Markatos, K.E. Kakosimos, Mathematical modelling 567 and computer simulation of toxic gas building infiltration, Process Safety and Environmental 568 Protection $111(2017)$ 687-700.

569 [23] H.-W. Kuo, H.-Y. Shen, Indoor and outdoor PM2.5 and PM10 concentrations in the air 570 during a dust storm, Build. Environ. 45 (2010) 610-614. 
571 [24] K. Kanatani, M. Okumura, S. Tohno, Y. Adachi, K. Sato, T. Nakayama, Indoor particle

572 counts during Asian dust events under everyday conditions at an apartment in Japan,

573 Environmental Health and Preventive Medicine 19(1) (2014) 81-88.

574 [25] H. Krasnov, I. Katra, M.D. Friger, Insights into Indoor/Outdoor PM Concentration Ratios

575 due to Dust Storms in an Arid Region, Atmosphere 6(7) (2015) 879-890.

576 [26] N.H. Wong, B. Huang, Comparative study of the indoor air quality of naturally ventilated

577 and air-conditioned bedrooms of residential buildings in Singapore, Build. Environ. 39(9) (2004) $578 \quad 1115-1123$

579 [27] E. Diapouli, A. Chaloulakou, P. Koutrakis, Estimating the concentration of indoor particles 580 of outdoor origin: A review, J. Air Waste Manage. Assoc. 63 (2013) 1113-1129.

581 [28] C.D. Argyropoulos, S. Elkhalifa, E. Fthenou, G.C. Efthimiou, S. Andronopoulos, A. 582 Venetsanos, I.V. Kovalets, K.E. Kakosimos, Source reconstruction of airborne toxics based on 583 acute health effects information, Scientific Reports 8(1) (2018) 5596.

584 [29] A.M. Ashraf, C.D. Argyropoulos, T. Olewski, L. Vechot, K.E. Kakosimos, Comparative 585 study on toxic gas infiltration in a non-process area using CFD and multi-zone models, Institution 586 of Chemical Engineers Symposium Series, 2016.

587 [30] D.J. Hall, A.M. Spanton, Ingress of external contaminants into buildings - A review, UK 588 Atmospheric Dispersion Modelling Liaison Committee, 2012.

589 [31] C. Chen, B. Zhao, Review of relationship between indoor and outdoor particles: I/O ratio, 590 infiltration factor and penetration factor, Atmos. Environ. 45(2) (2011) 275-288.

591 [32] P. Amoatey, H. Omidvarborna, M.S. Baawain, A. Al-Mamun, Indoor air pollution and 592 exposure assessment of the gulf cooperation council countries: A critical review, Environ. Int. 593 $121(2018)$ 491-506. 
594 [33] L.L. Wang, W.S. Dols, Q. Chen, Using CFD capabilities of CONTAM 3.0 for simulating 595 airflow and contaminant transport in and around buildings, HVAC\&R Research 16 (2010) 749596763.

597 [34] M. Nelson, M. Brown, The Quick Urban \& Industrial Complex (QUIC) dispersion modeling 598 system, Los Alamos National Laboratory, 2013.

599 [35] A. Schaelin, V. Dorer, J. Van der Maas, A. Moser, Improvement of multizone model 600 predictions by detailed flow path values from CFD calculations, ASHRAE Transactions 99(2) $601 \quad(1993) 709$.

602 [36] A. Musser, An analysis of combined CFD and multi-zone IAQ model assembly issues, 603 ASHRAE Transactions 107 (2001) 371-382.

604 [37] L. Wang, Q. Chen, Theoretical and numerical studies of coupling multizone and CFD 605 models for building air distribution simulations, Indoor Air 17(5) (2007) 348-361.

606 [38] J. Srebric, J. Yuan, A. Novoselac, On-site experimental validation of a coupled multizone 607 and CFD model for building contaminant transport simulations, ASHRAE Transactions 114(1) $608 \quad(2008) 273-281$.

609 [39] A.E. Chatzimichailidis, C.D. Argyropoulos, M.J. Assael, K.E. Kakosimos, Qualitative and 610 quantitative investigation of multiple large eddy simulation aspects for pollutant dispersion in 611 street canyons using OpenFOAM, Atmosphere 10(1) (2019).

612 [40] C.D. Argyropoulos, M. Abraham, H. Hassan, A.M. Ashraf, E. Fthenou, E. Sadoun, K.E. 613 Kakosimos, Modeling of $\mathrm{PM}_{10}$ and $\mathrm{PM}_{2.5}$ building infiltration during a dust event in Doha, Qatar, 614 2nd International Conference on Atmospheric Dust, Castellaneta Marina, Italy, 2016.

615 [41] D.E. Saraga, T. Maggos, K.E. Kakosimos, E. Fthenou, H. Hassan, Z. Truman, V. Tsiouri, S. 616 Karavoltsos, A. Sakellari, C. Vasilakos, E. Sadoun, Chemical Characterization of indoor and 
617 outdoor PM2.5, PM10 and VOCs in a public building in Doha City, Qatar, 14th International 618 Conference of Indoor Air Quality and Climate, Ghent, Belgium, 2016.

619 [42] Grimm, Manual, Environ Check 365, Grimm Aerosol Technik GmbH\&Co KG, Germany, 620 (2005).

621 [43] D. Saraga, T. Maggos, E. Sadoun, E. Fthenou, H. Hassan, V. Tsiouri, S. Karavoltsos, A. 622 Sakellari, C. Vasilakos, K. Kakosimos, Chemical characterization of indoor and outdoor 623 particulate matter (PM2.5, PM10) in Doha, Qatar, Aerosol and Air Quality Research 17(5) 624 (2017) 1156-1168.

625 [44] M.V. Swami, S. Chandra, Correlations for pressure distributions on buildings and 626 calculations of natural-ventilation airflow, ASHRAE Transactions 94 (1998) 243-266.

627 [45] F. Haghighat, A.C. Megri, A comprehensive validation of two airflow models - COMIS and 628 CONTAM, Indoor Air 6 (1996) 278-288.

629 [46] P. Fabian, G. Adamkiewicz, J.I. Levy, Simulating indoor concentrations of NO2 and PM2.5 630 in multifamily housing for use in health-based intervention modeling, Indoor Air 22(1) (2012) $631 \quad 12-23$.

632 [47] C. Shrubsole, I. Ridley, P. Biddulph, J. Milner, S. Vardoulakis, M. Ucci, P. Wilkinson, Z. 633 Chalabi, M. Davies, Indoor PM2.5 exposure in London's domestic stock: Modelling current and 634 future exposures following energy efficient refurbishment, Atmos. Environ. 62 (2012) 336-343.

635 [48] D. Rim, A. Persily, S. Emmerich, W.S. Dols, L. Wallace, Multi-zone modeling of size636 resolved outdoor ultrafine particle entry into a test house, Atmos. Environ. 69 (2013) 219-230.

637 [49] F. Li, E.S. Lee, J. Liu, Y. Zhu, Predicting self-pollution inside school buses using a CFD and 638 multi-zone coupled model, Atmos. Environ. 107 (2015) 16-23.

639 [50] G.N. Walton, AIRNET - A computer program for building airflow network modeling, 640 National Institute of Standards and Technology, NISTIR 89-4072, 1989. 
641 [51] G.N. Walton, W.S. Dols, CONTAM 2.4 User Guide and Program Documentation, National 642 Institute of Standards and Technology, Gaithersburg, MD, 2005.

643 [52] W.S. Dols, B.J. Polidoro, CONTAM user guide and program documentation, NIST, 644 Technical Note 1887, Version 3.2, 2015.

645 [53] B. Singh, B.S. Hansen, M.J. Brown, E.R. Pardyjak, Evaluation of the QUIC-URB fast 646 response urban wind model for a cubical building array and wide building street canyon, Environ. 647 Fluid Mech. 8(4) (2008) 281-312.

648 [54] M. Neophytou, A. Gowardhan, M. Brown, An inter-comparison of three urban wind models 649 using Oklahoma City Joint Urban 2003 wind field measurements, J. Wind Eng. Ind. Aerodyn. 650 99(4) (2011) 357-368.

651 [55] M. Nelson, M.J. Brown, S.A. Halverson, P.E. Bieringer, A. Annunzio, G. Bieberbach, S. 652 Meech, A case study of the weather research and forecasting model applied to the Joint Urban 6532003 tracer field experiment. Part 2: Gas tracer dispersion, Boundary Layer Meteorol. (2016).

654 [56] R. Röckle, Bestimmung der Strömungsverhältnisse im Bereich komplexer 655 Bebauungsstrukturen, Vom Fachbereich Mechanik, der Technischen Hochschule Darmstadt, 656 Germany, 1990.

657 [57] C.A. Sherman, A Mass-Consistent Model for Wind Fields over Complex Terrain, J. Appl. 658 Meteorol. 17(3) (1978) 312-319.

659 [58] A. Gowardhan, E. Pardyjak, I. Senocak, M. Brown, A CFD-based wind solver for an urban 660 fast response transport and dispersion model, Environ. Fluid Mech. 11(5) (2011) 439-464.

661 [59] V.L. Prandtl, Magnuseffekt und Windkraftschiff, Zeitschrift fuer Angewandte Matematik 662 und Mechanik 5 (1925) 136-139.

663 [60] C.D. Argyropoulos, N.C. Markatos, Recent advances on the numerical modelling of 664 turbulent flows, Applied Mathematical Modelling 39(2) (2015) 693-732. 
665 [61] H.K. Versteeg, W. Malalasekera, An Introduction to Computational Fluid Dynamics: The 666 Finite Volume Method, 2nd edition, Pearson Education Limited, England2007.

667 [62] N. Gopalaswami, K. Kakosimos, L. Vèchot, T. Olewski, M.S. Mannan, Analysis of 668 meteorological parameters for dense gas dispersion using mesoscale models, J. Loss Prev. 669 Process Ind. 35(0) (2015) 145-156.

670 [63] J. Franke, A. Hellsten, H. Schlünzen, B. Carissimo, Cost Action 732: Best Practice 671 Guideline for the CFD Simulation of Flow in the Urban Environment, Quality assurance and 672 impovement of microscale meteorological models, Cost Office, 2007.

673 [64] R.R. Draxler, D.A. Gillette, J.S. Kirkpatrick, J. Heller, Estimating PM10 air concentrations 674 from dust storms in Iraq, Kuwait and Saudi Arabia, Atmos. Environ. 35(25) (2001) 4315-4330. 675 


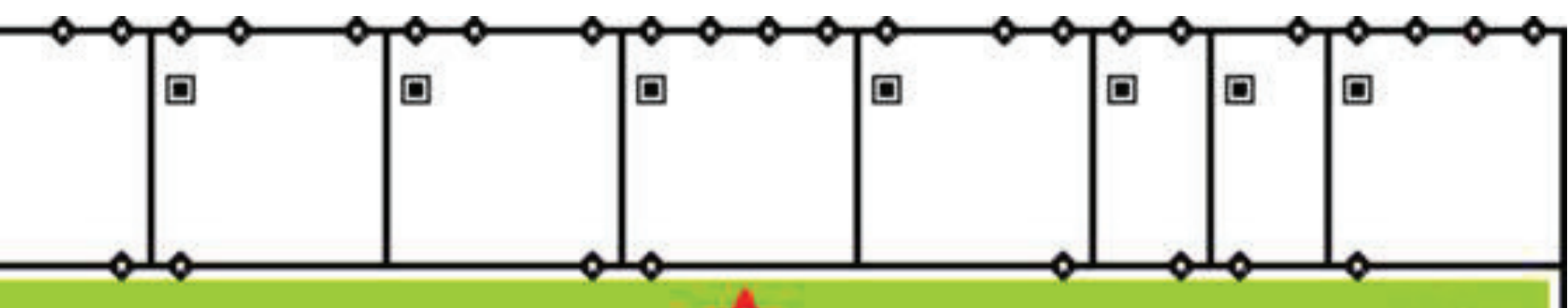

\section{3rd floor, Reception Area}
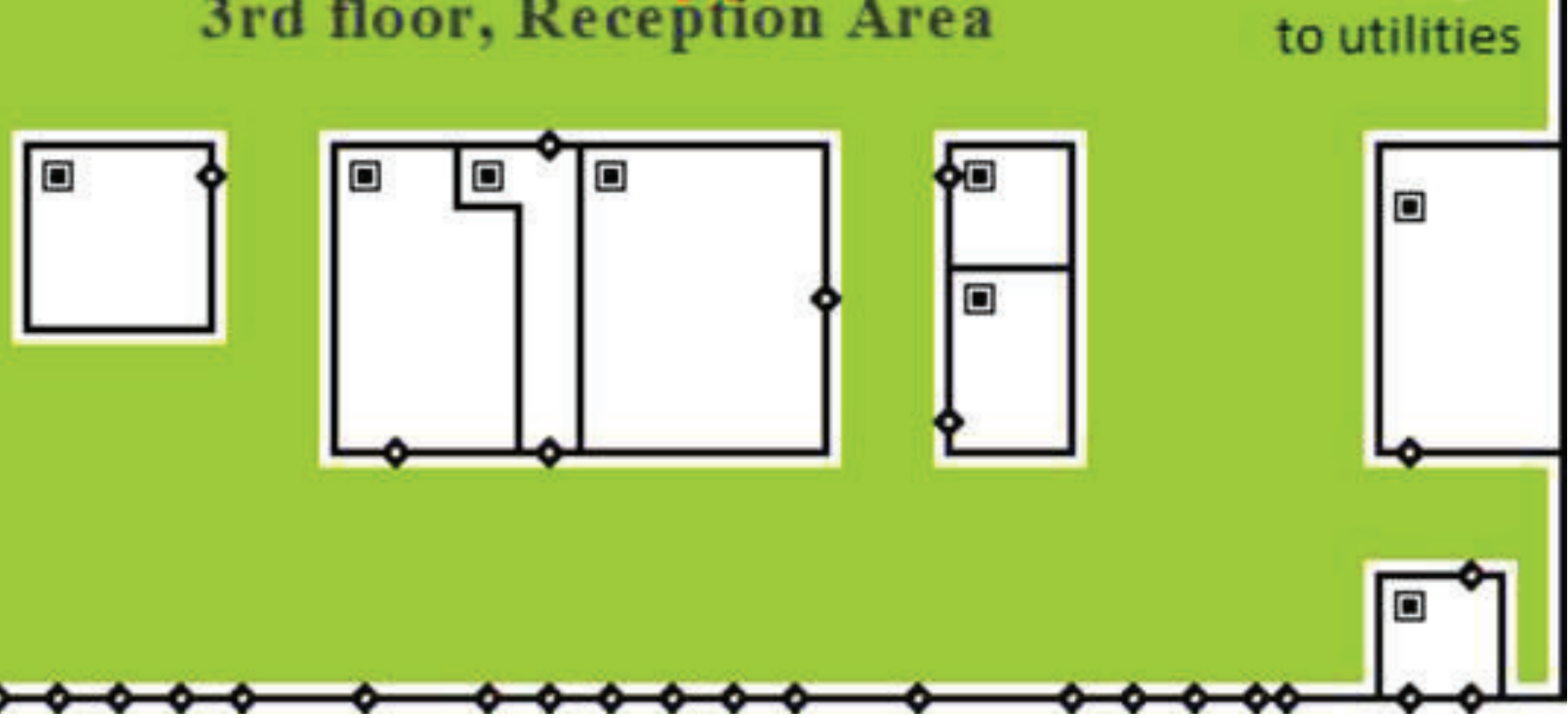


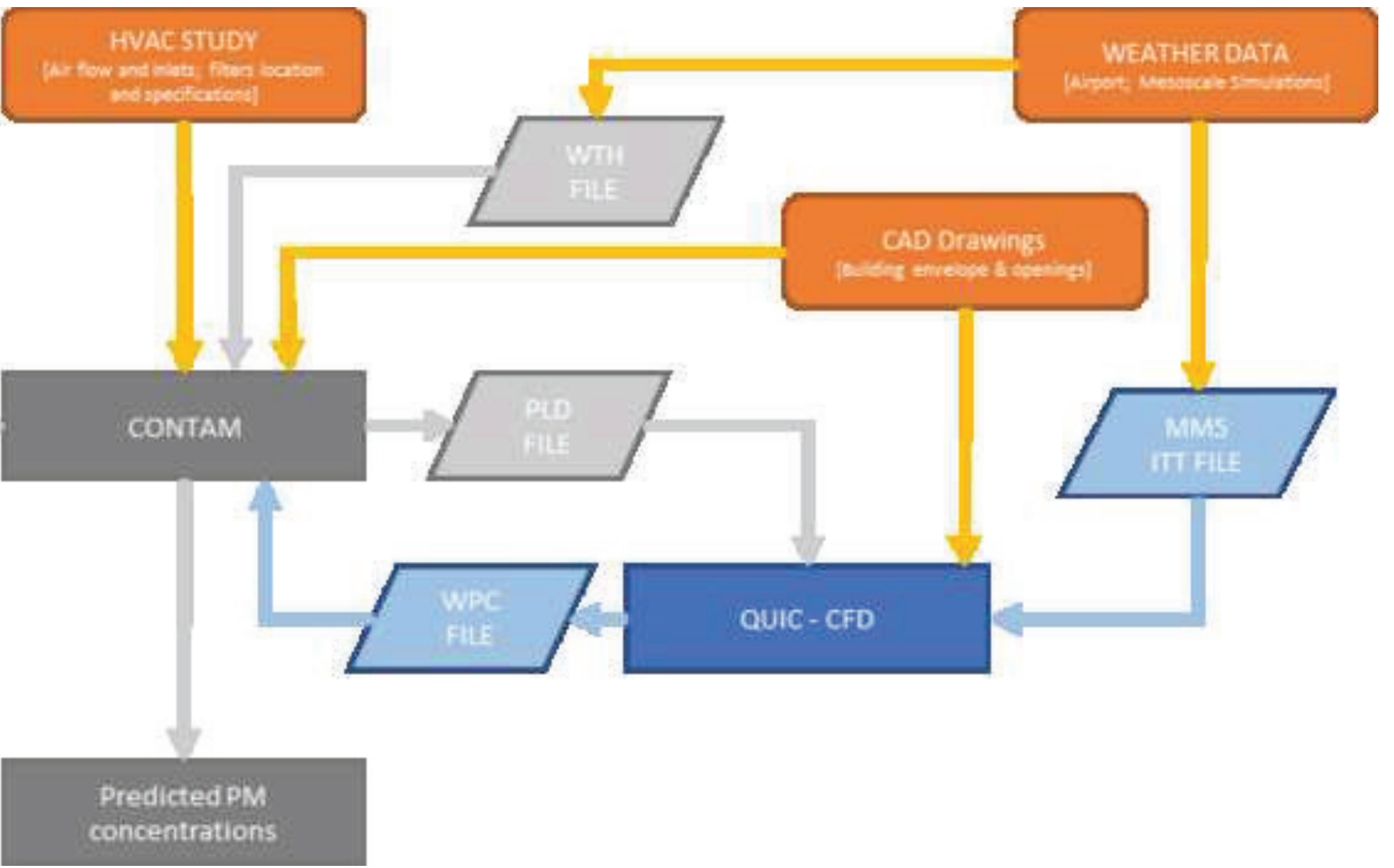


(a)

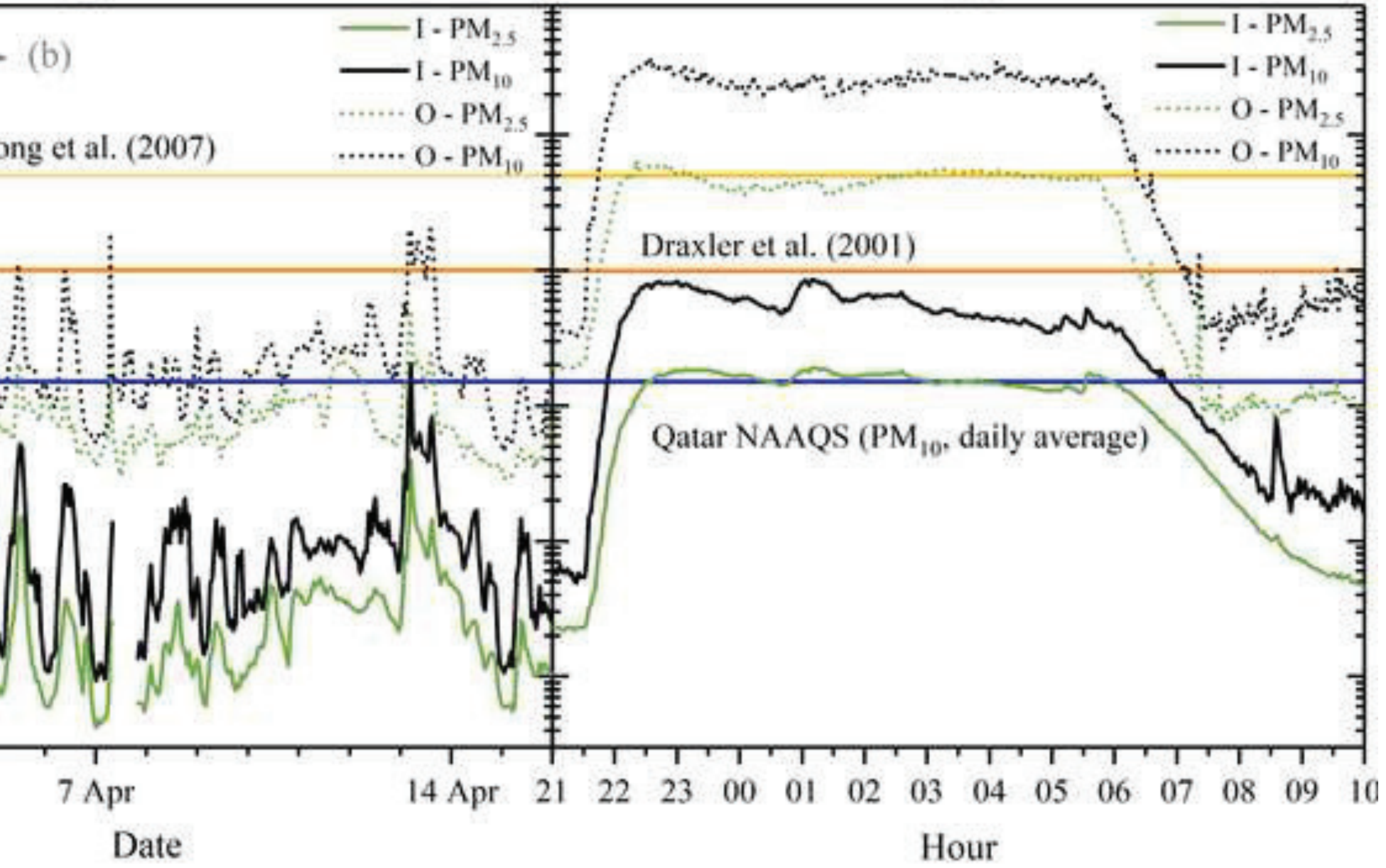

(b) 


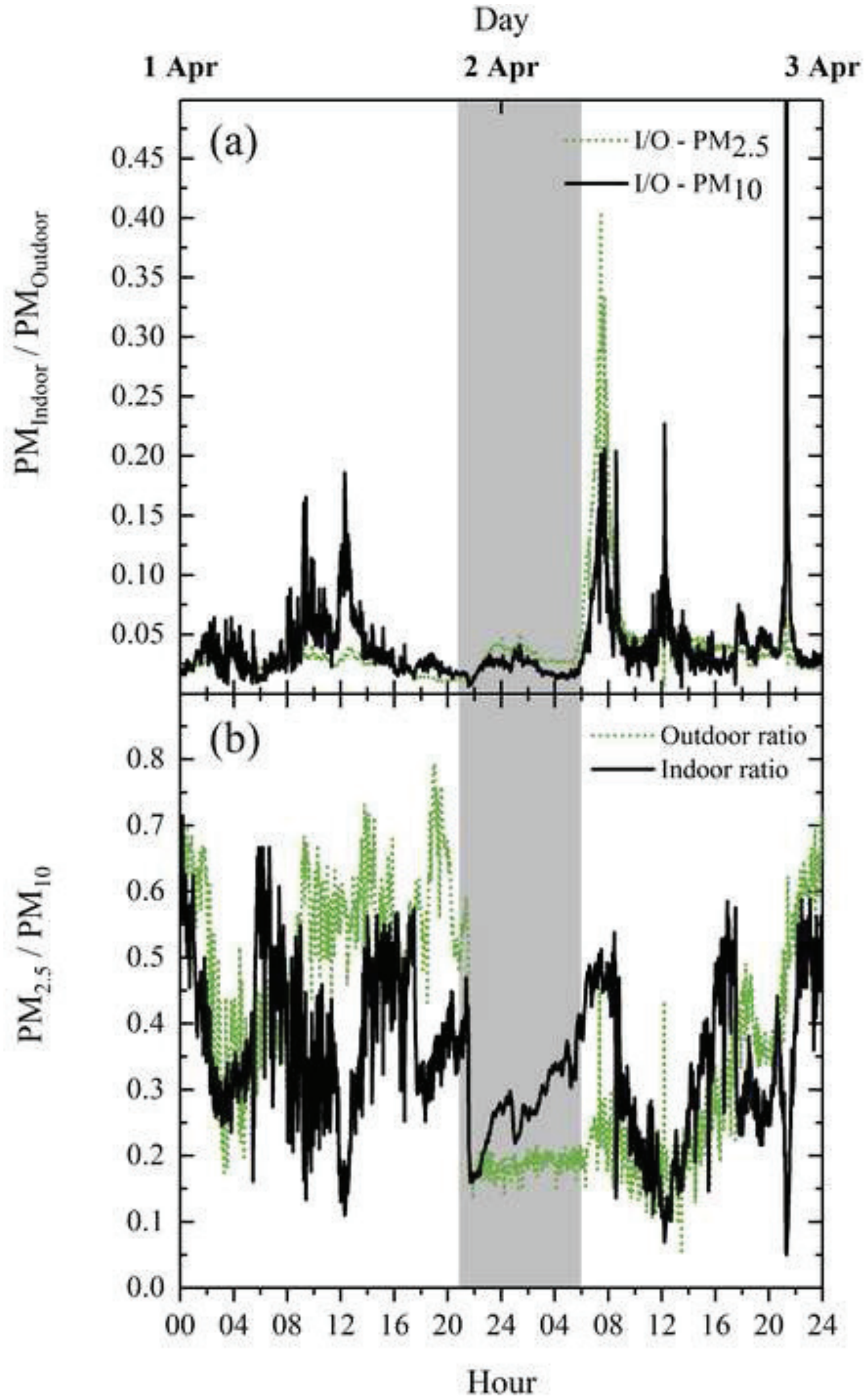


(a)

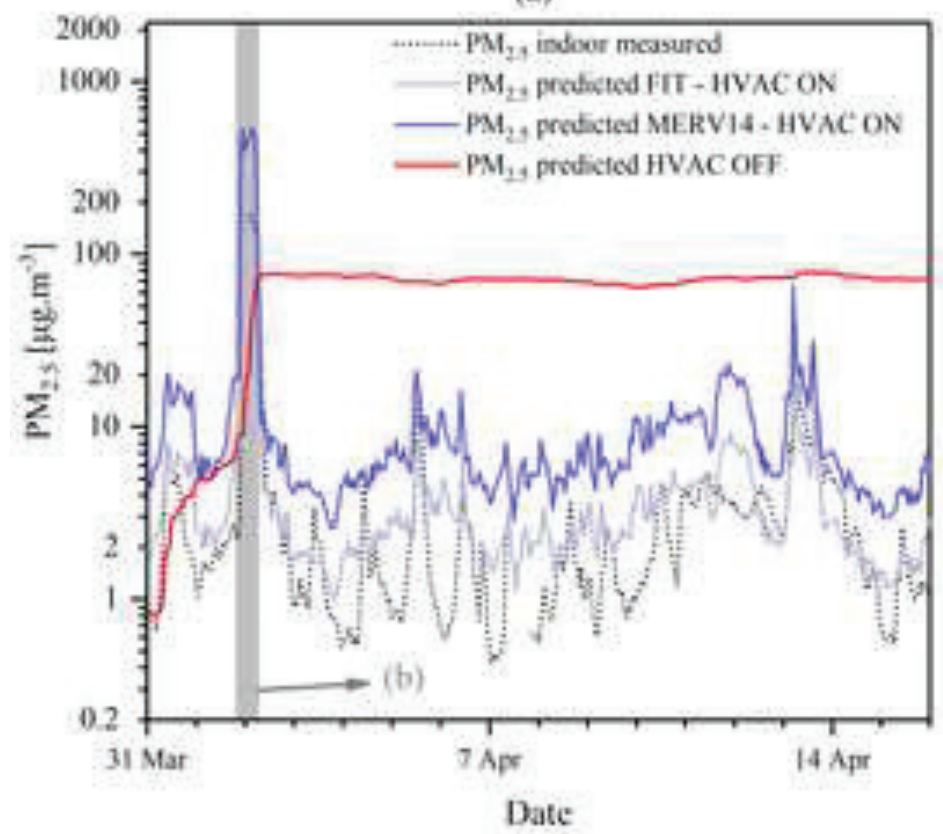

(c)

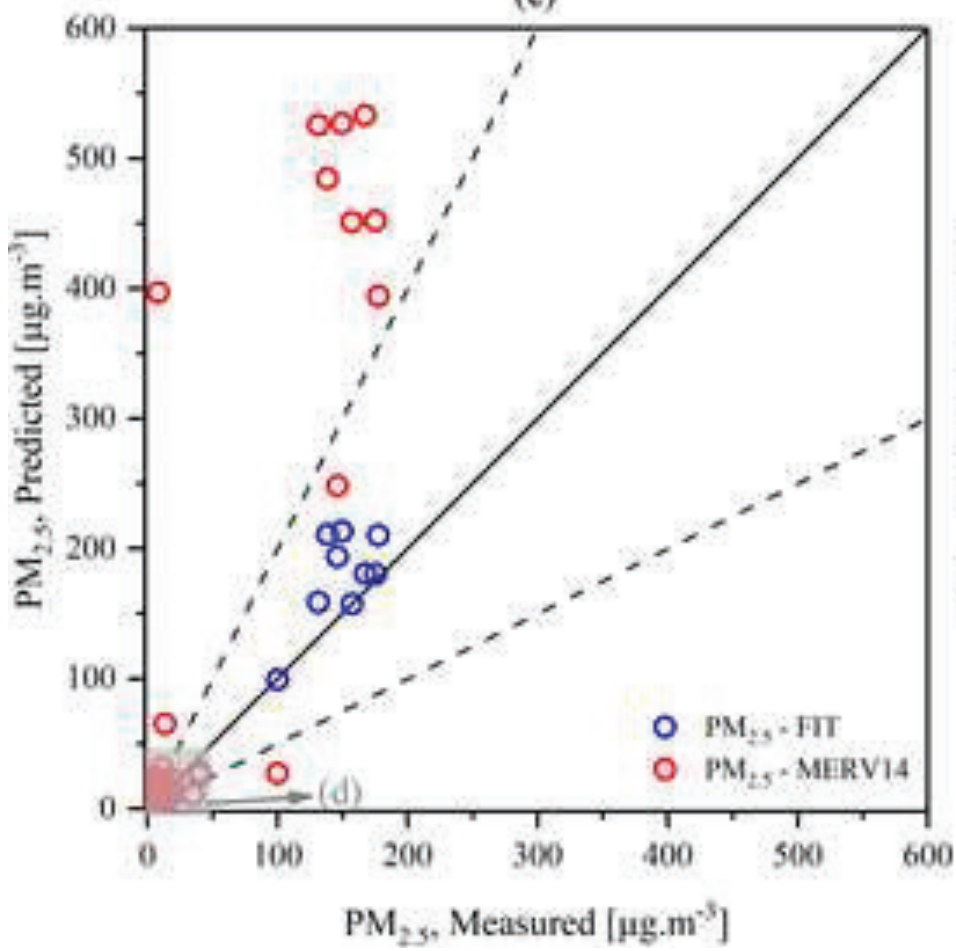

(b)

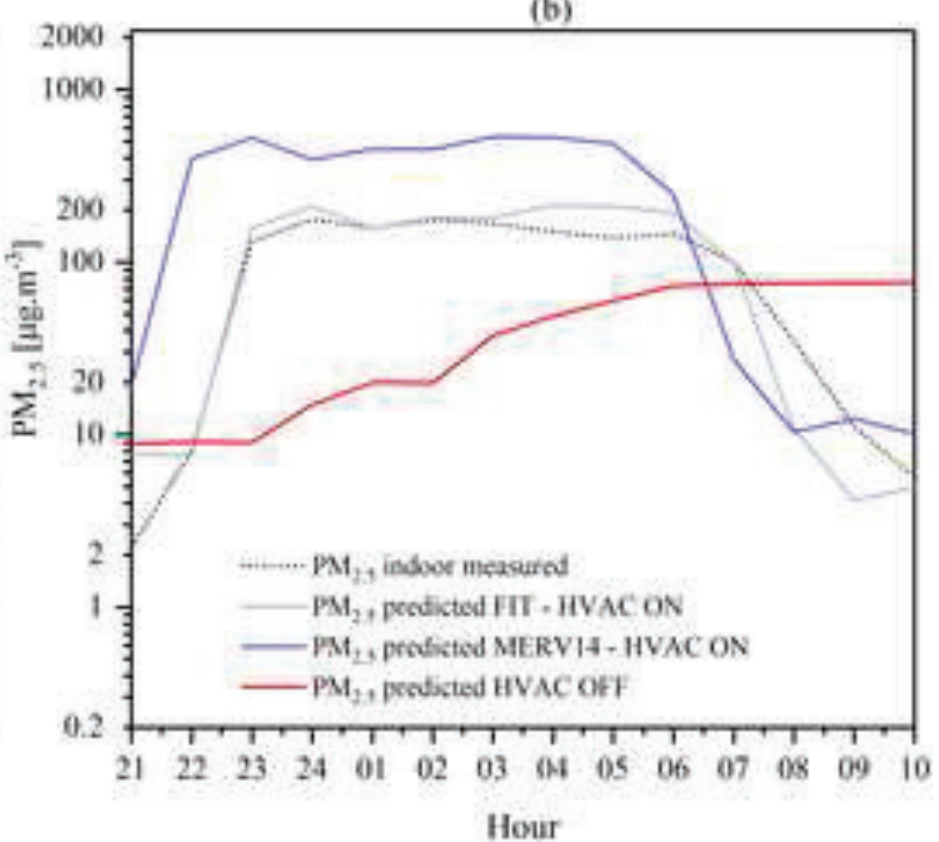

(d)

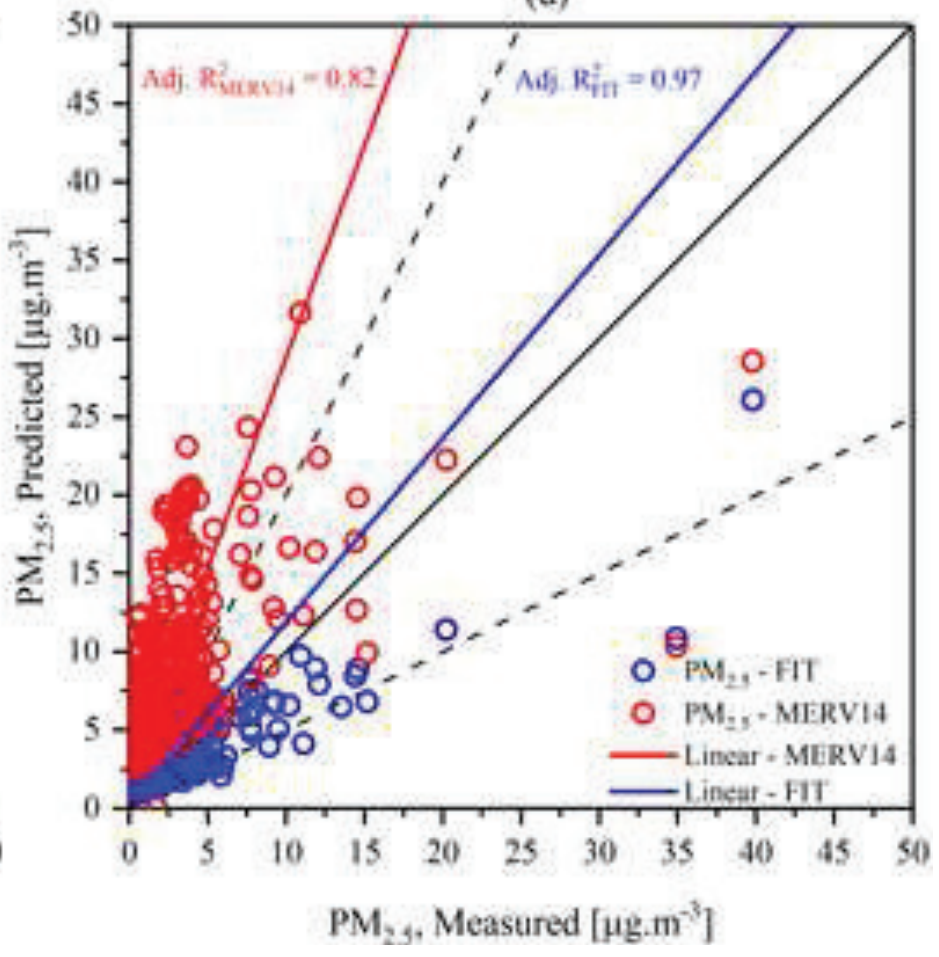


(a)

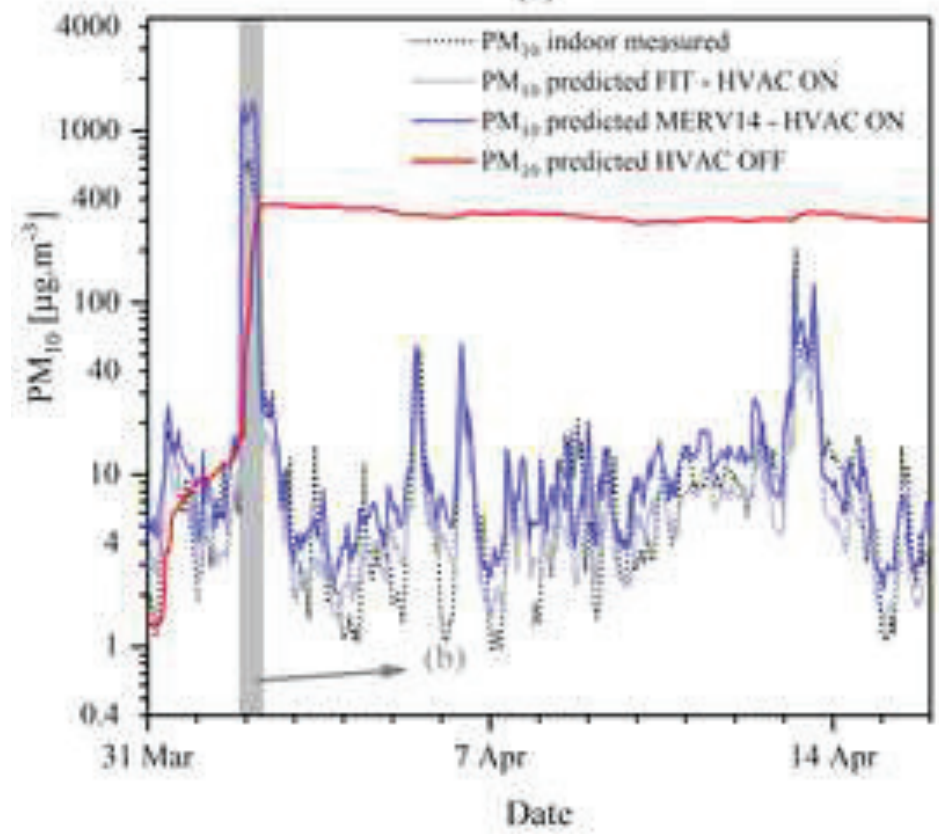

(c)

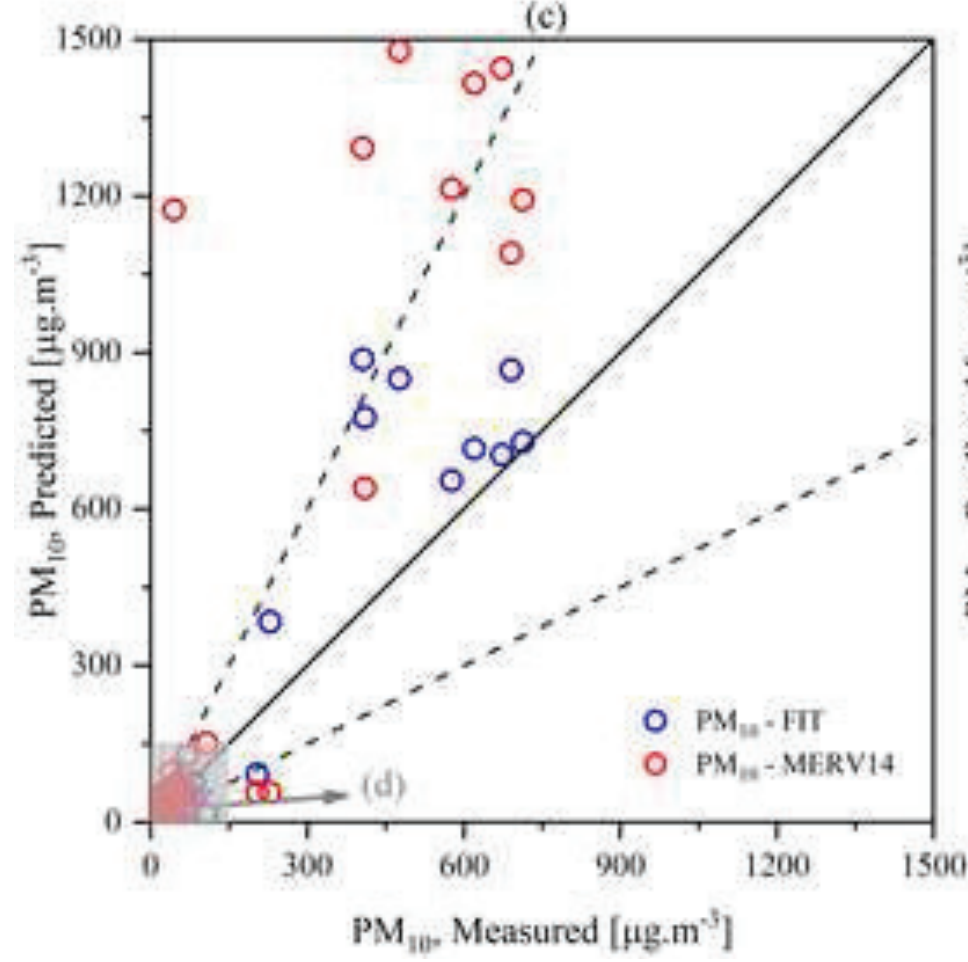

(b)

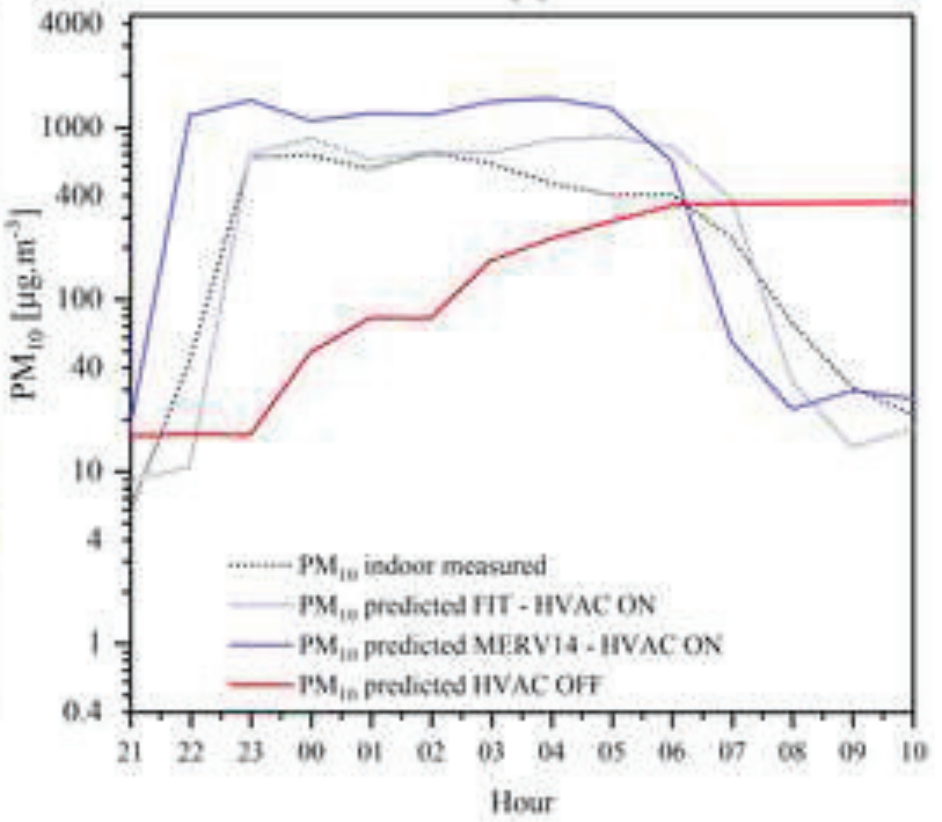

(d)

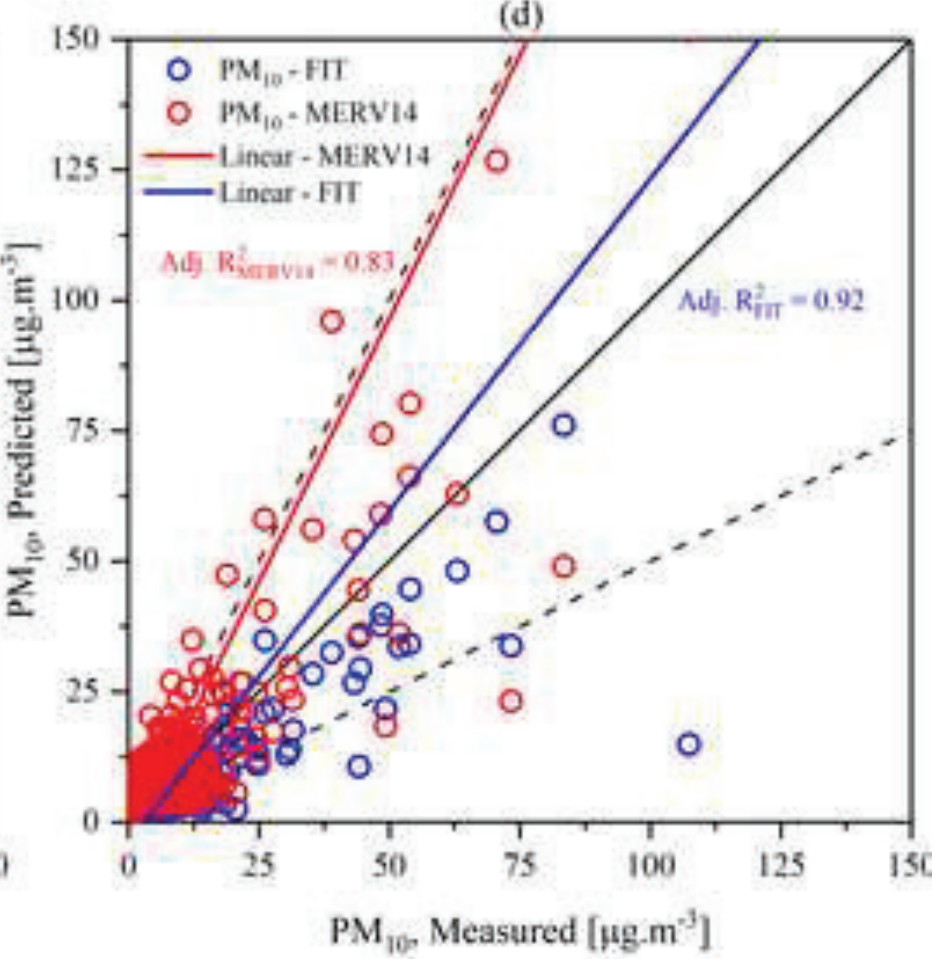


(a)

(b)

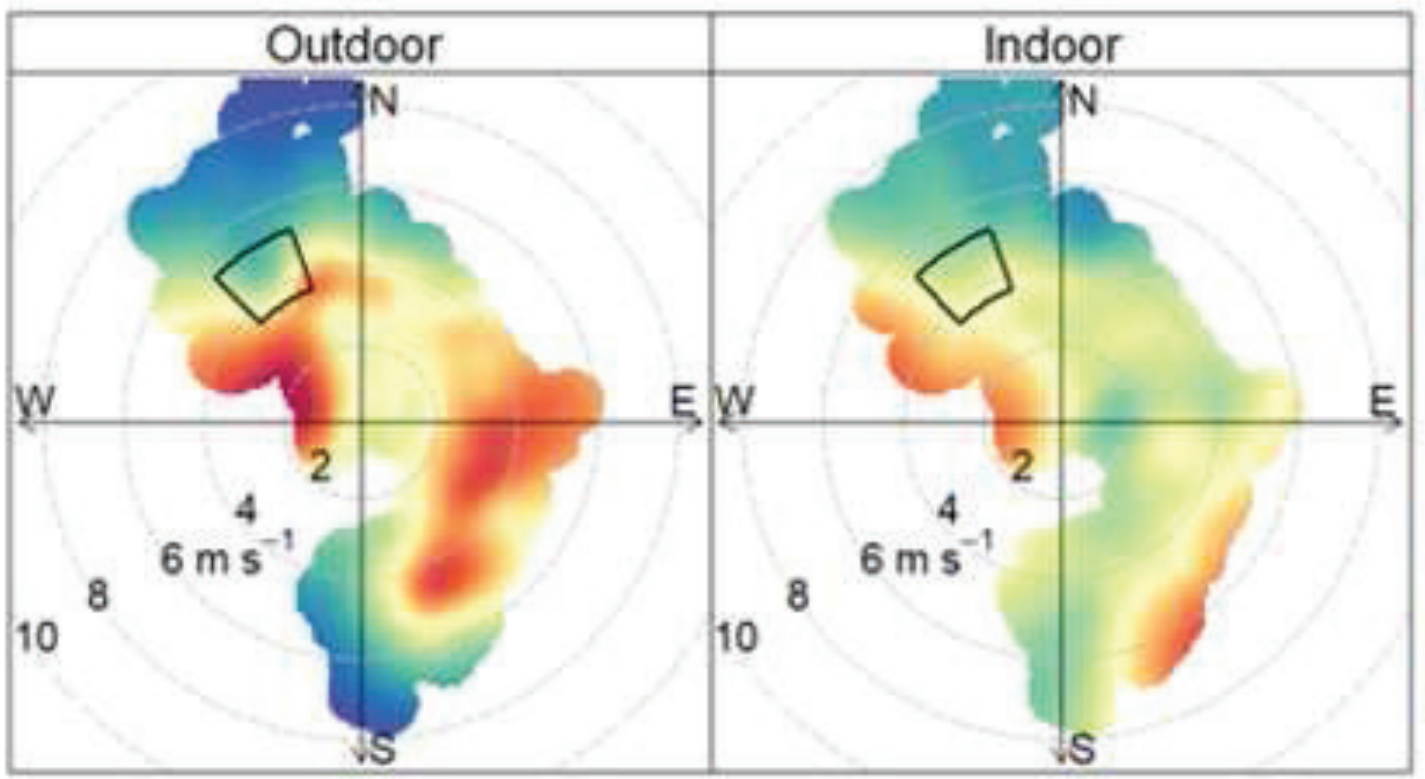

(d)

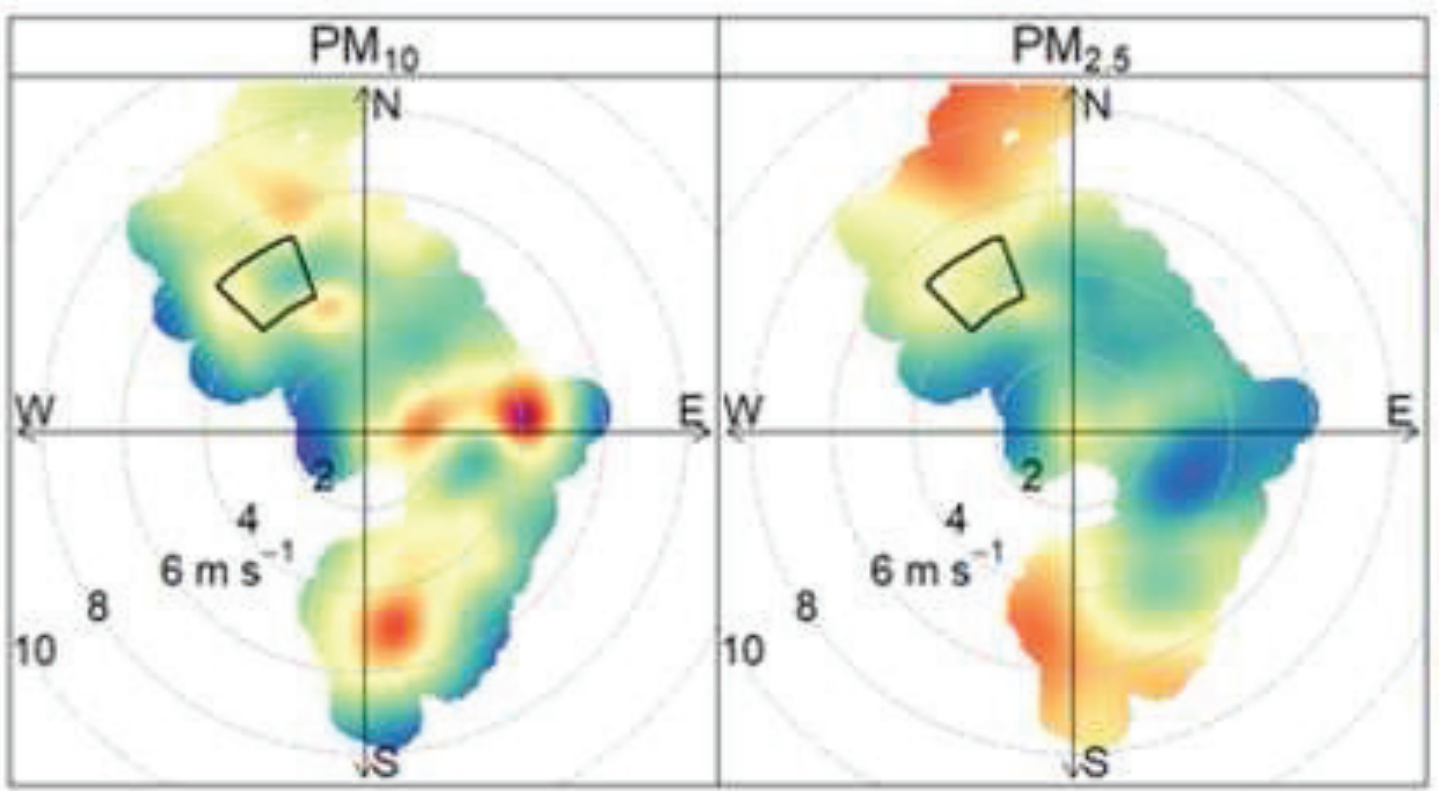

mean

0.07

0.06

0.05

0.04

0.03

0.02

1/O

(c)

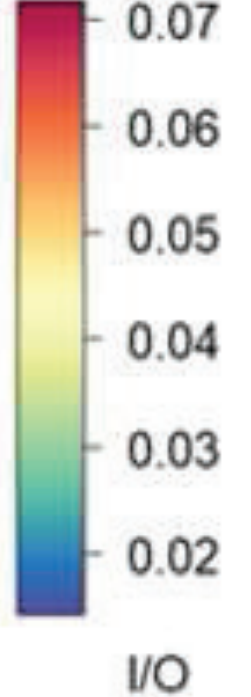

